pp 1702-1739. (C) The Author(s), 2020. Published by Cambridge University Press on behalf of Royal Aeronautical Society. This is an Open Access article, distributed under the terms of the Creative Commons Attribution licence (http://creativecommons.org/licenses/by/4.0/), which permits unrestricted re-use, distribution, and reproduction in any medium, provided the original work is properly cited.

doi:10.1017/aer.2020.46

\title{
Modelling performance an air transport network operated by subsonic and supersonic aircraft
}

\author{
M. Janić \\ M.Janic@tudelft.nl \\ milanjanic3@gmail.com \\ Department of Transport \& Planning, Faculty of Civil Engineering and Geosciences \\ Delft University of Technology \\ Stevinweg, 2628 BX \\ Delft \\ The Netherlands
}

\section{ABSTRACT}

This paper deals with modelling the performance of an air transport network operated by existing subsonic and the prospective supersonic commercial aircraft. Analytical models of indicators of the infrastructural, technical/technological, operational, economic, environmental, and social performance of the network relevant for the main actors/stakeholders involved are developed. The models are applied to the given long-haul air route network exclusively operated by subsonic and supersonic aircraft according to the specified "what-if" scenarios.

The results from application of the models indicate that supersonic flights powered by $\mathrm{LH}_{2}$ (Liquid Hydrogen) could be more feasible than their subsonic counterparts powered by Jet A fuel, in terms of about three times higher technical productivity, $46 \%$ smaller size of the required fleet given the frequency of a single flight per day, $20 \%$ lower sum of the aircraft/airline operational, air passenger time, and considered external costs, up to two times higher overall social-economic feasibility, and 94\% greater savings in contribution to global warming and climate change. These flights could be less feasible in terms of about $70-85 \%$ higher aircraft/airline operational costs, $70 \%$ and $19 \%$ higher fuel consumption and emissions of Green House Gases, respectively, and 6-13\% higher noise compared to the specified acceptable levels.

Keywords: Air route network; performance; indicators; modelling; subsonic and supersonic aircraft/flights; social-economic feasibility 


\section{NOMENCLATURE}

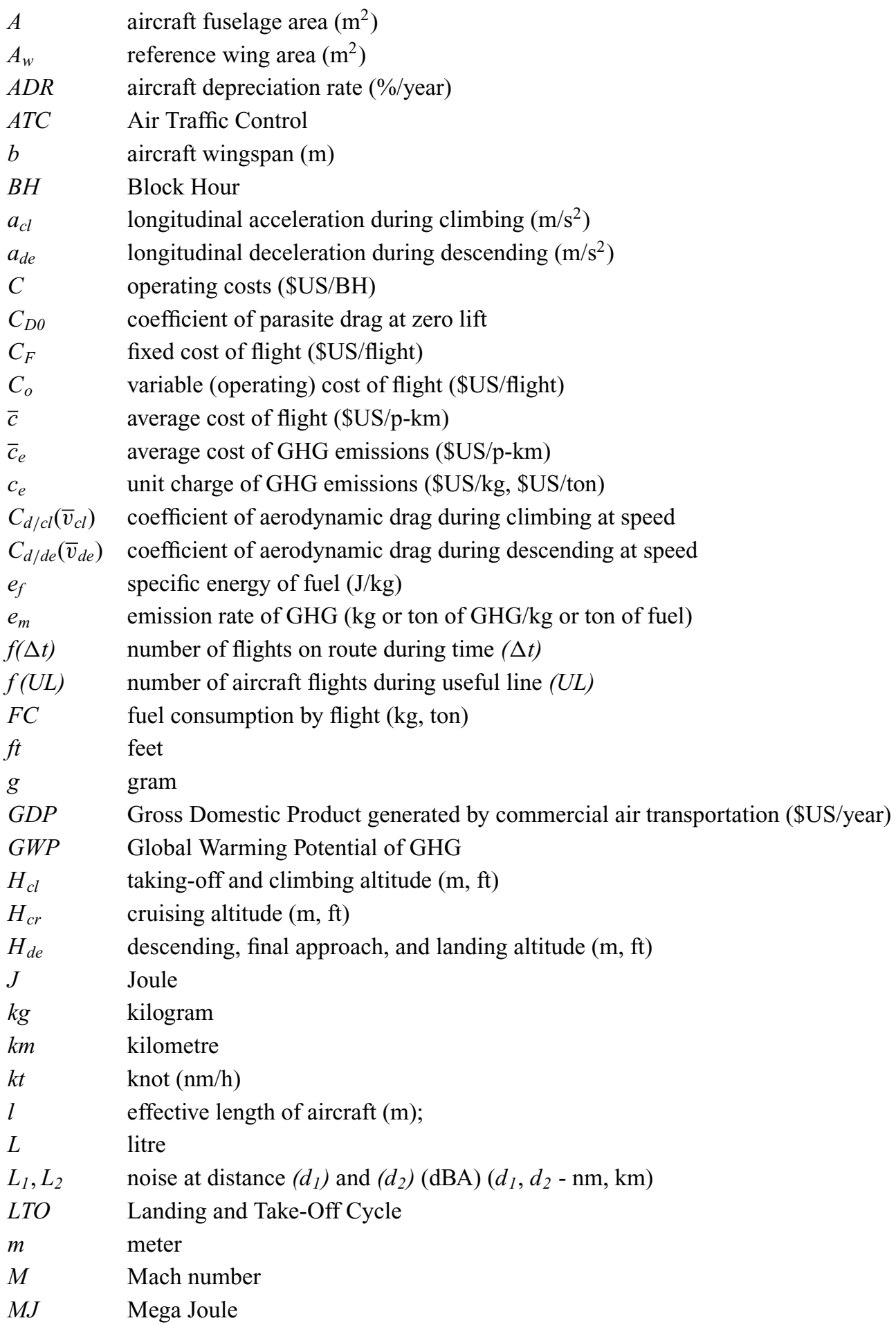




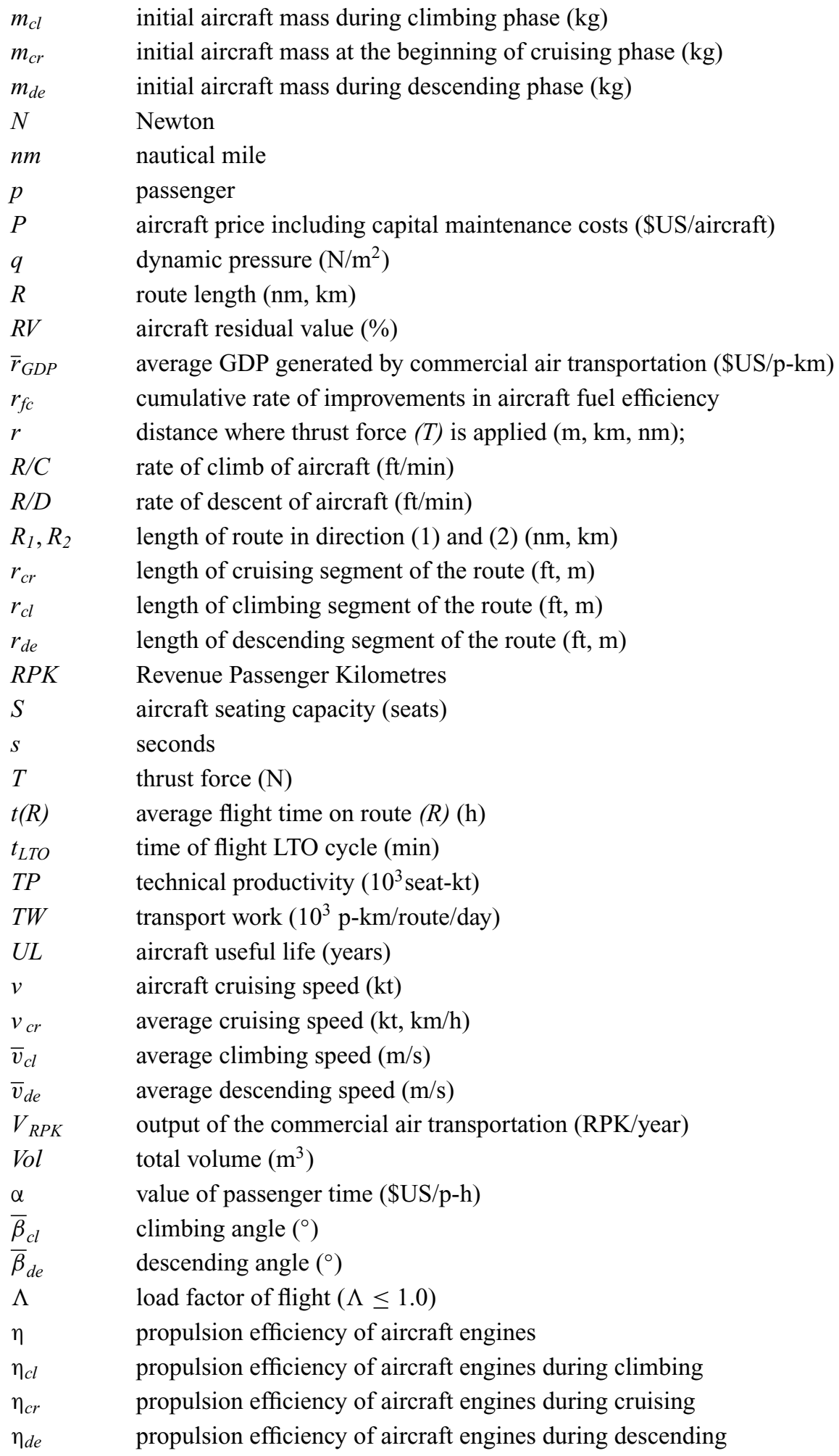




\begin{tabular}{|c|c|}
\hline$n(\Delta \tau)$ & required aircarft fleet for the network \\
\hline $\bar{\rho}_{c l}$ & average air density along climbing segment of the route $\left(\mathrm{kg} / \mathrm{m}^{3}\right)$ \\
\hline$\rho_{c r}$ & air density at cruising altitude $\left(\mathrm{kg} / \mathrm{m}^{3}\right)$ \\
\hline $\bar{\rho}_{d e}$ & average air density along descending segment of the route $\left(\mathrm{kg} / \mathrm{m}^{3}\right)$ \\
\hline$\Theta$ & Mach angle $\left(^{\circ}\right)$ \\
\hline$\tau(R)$ & aircaft turnaround time on route $(R)(\mathrm{h})$ \\
\hline$\Delta \tau$ & time of scheduling flights (day) \\
\hline $\mathrm{CO}_{2}$ & Carbon Dioxide (kg/kg of fuel) \\
\hline $\mathrm{CO}_{2 e}$ & Carbon Dioxid Eqivalents \\
\hline$H C$ & Hydrocarbons ( $\mathrm{g} / \mathrm{kg}$ of fuel) \\
\hline $\mathrm{H}_{2} \mathrm{O}$ & Water Vapor $(\mathrm{kg} / \mathrm{kg}$ of fuel) \\
\hline $\mathrm{LH}_{2}$ & Liquid Hydrogen \\
\hline$N O_{x}$ & Nitrogen Oxides (g/kg of fuel) \\
\hline$P M$ & Particulate Matters (PM/kg of fuel) \\
\hline$S G$ & Specific Gravity (kg/L) \\
\hline$S E$ & Specific Energy (MJ/kg) \\
\hline$S O_{x}$ & Sulphur oxides ( $\mathrm{g} / \mathrm{kg}$ of fuel) \\
\hline
\end{tabular}

\subsection{INTRODUCTION}

Increasing of travel speed has been a human endeavour for a long time. In general, limitations on the time and monetary budget, maximizing travel distances during the shortest possible time and related costs have become the main driving forces in developing both inland HS (high speed) and air transport systems. A relatively simple calculation indicates that an increase in the operating speed generally brings marginal savings in the user/passenger travel time. These savings increase with increasing of the non-stop travel distance $(s)^{(1)}$. Under such conditions, the possible implementation of commercial supersonic aircraft seems to be beneficial primarily in the case of long-haul flights. Currently, these flights are carried out by commercial subsonic aircraft. Additionally, combined with the aircraft seat capacity and the flight frequency, the supersonic speed could substantialyl increase the air route(s) technical productivity and thus bring obvious gains to the airlines. However, these gains in travel time and technical productivity remain questionable after being counterbalanced by the overall economics of these flights, including their operational costs and the environmental and social externalities. The earliest but retired Concorde and TY 144 supersonic aircraft did not achieve such an acceptable social-economic balance. Therefore, the question is whether the design and operational concepts of forthcoming supersonic aircraft, combined with an innovative consideration, could possibly indicate elements of their positive social-economic feasibility? This paper provides a framework for assessing this balance through modelling performance indicators of the given long-haul air route network, operated exclusively by supersonic aircraft or their subsonic counterparts, according to the given "what-if" scenarios.

Modelling implies development of the analytical models of particular indicators.

The considered performances are infrastructural, technical/technological, operational, economic, environmental, and social.

Infrastructural performance relates to airports as network nodes and the air routes connecting them as the network links. The airports and air routes can accommodate both subsonic and supersonic aircraft safely, efficiently, and effectively. 
Technical/technological performance is considered as directly related to the design of both considered categories of aircraft. These are: length (m), wing aspect ratio, L/D (lift-to-drag) ratio, take-off weight (tons), number of engines (-), take-off speed (kt), cruising speed (Mach), landing speed (kt), range (nm; km), payload (seats), payload/weight ratio (-), fuel/weight ratio $(-)$, and payload/fuel ratio $(-)^{(13)}$. In the further consideration, these are exclusively used as the given case-based parameters.

Operational performance relates to the passenger demand and the supply of transport capacities serving this demand, under the given condition. In general, these are the flight frequency by the given aircraft type(s) and load factor, the air route travel time, the aircraft turnaround time, the route and network transport work and technical productivity, and the fleet size ${ }^{(13)}$.

Economic performance is considered to be the flight(s) operating cost (as the basis for setting up airfares), the cost of passenger time while on board the flight(s), contribution to the regional/national gross domestic product (GDP), and the overall social-economic feasibility.

Environmental performance includes the aircraft/flight fuel consumption and related emissions of greenhouse gases (GHG), their costs, i.e. externalities, and the contribution of GHG emissions to global warming and climate change.

Social performance relates to the aircraft noise around airports and along the network routes (the latter by supersonic aircraft/flights), congestion/delays, safety, i.e. the risk of incidents/accidents, and their corresponding costs, i.e. externalities.

These performances are considered relevant for the particular actors/stakeholders involved. These can be the aerospace manufacturers, airlines, airports, users/air passengers, local communities, and aviation and non-aviation regulatory bodies and policy makers at the local, regional, national, or international level.

In addition to this introductory section, the paper consists of five other sections. Section 2 presents an overview of research and development of commercial subsonic and supersonic aircraft. Section 3 deals with development of the analytical models of performance indicators of the given long-haul air route network. This consists of airports as network nodes and air routes with the non-stop flights connecting them as the network links. Section 4 shows an application of the models of performance indicators to an existing long-haul air route network. This network consists of 25 longest air routes where the current subsonic flights are assumed to be completely replaced by their supersonic counterparts in the year 2050 . The last Section (5) summarises some conclusions.

\subsection{DEVELOPMENT OF COMMERCIAL SUBSONIC AND SUPERSONIC AIRCRAFT}

\subsection{Commercial subsonic aircraft}

The commercial subsonic aircraft considered in the given context have been typically characterised by their range $(R)$, seat capacity $(S)$, and cruising speed ( $v)$. By the year 2011, their range $(R)$ had increased to about $7500 \mathrm{~nm}$, seat capacity $(S)$ to 550 seats, and cruising speed (v) to about $500 \mathrm{kt}(926 \mathrm{~km} / \mathrm{h})$, i.e., $M=0.87(M-\text { Mach number })^{(2),(3),(4)}$. Such developments have generally influenced technical productivity $(T P)^{(3)}$, operational costs $(C)^{(49,53)}$, and fuel consumption $(F C)^{(9,67-71)}$ of the corresponding flights. Examples of their causal (regression) relationships are given by Eq. $1(\mathrm{a}, \mathrm{b}, \mathrm{c})$ as follows: 
- Technical productivity

$$
\begin{aligned}
& T P(S, v)=-17.335+0.432 \cdot S+0.071 \cdot v \\
& t(-2.654)(15.000)(5.907) \\
& R^{2}=0.983 ; F=177.497 ; D W=1.387 ; N=11 \\
& (139 \leq R \leq 6800 \mathrm{~nm} ; 241 \leq S \leq 544)
\end{aligned}
$$

- Operating costs

$$
\begin{aligned}
& C(R, S)=177.479+0.301 \cdot R+21.956 \cdot S \\
& t(0.285)(1.764)(4.967) \\
& R^{2}=0.712 ; F=82.655 ; D W=1.636 ; N=70 \\
& (139 \leq R \leq 6800 \mathrm{~nm} ; 241 \leq S \leq 544)
\end{aligned}
$$

- Fuel consumption

$$
\begin{aligned}
& F C(R, S)=\left(1-r_{f c}\right) \cdot(-107.149+0.00953 \cdot R+0.280 \cdot S) \\
& t(-13.013)(12.707)(11.809) \\
& R^{2}=0.957 ; F=267.980 ; D W=2.536 ; N=27 \\
& (6000 \leq R \leq 13500 \mathrm{~km} ; 241 \leq S \leq 544)
\end{aligned}
$$

$T P(S, v) \quad$ technical productivity $\left(10^{3}\right.$ seat-kt $)$

$C(R, S) \quad$ operating costs ( $\$ \mathrm{US} / \mathrm{BH})(\mathrm{BH}$ - block hour)

$F C(R, S)$ fuel consumption (tons/flight)

$S \quad$ aircraft capacity (seats)

$V \quad$ aircraft cruising speed $(\mathrm{kt})(1 \mathrm{kt}=1 \mathrm{~nm} / \mathrm{h} ; \mathrm{nm}$-nautical mile $)$

$R \quad$ route length $(\mathrm{nm} ; \mathrm{km})$

$r_{f c} \quad$ cumulative rate of improvements in aircraft fuel efficiency by the year (2050 vs 2019/2020)

As can be seen, technical productivity $(T P)$, (operational) cost $(C)$, and fuel consumption $(F C)$ have been strongly driven by the aircraft capacity $(S)$, cruising speed $(v)$, and range $(R)$. Aircraft capacity $(S)$ has been the strongest driving force in all three relationships. In addition to fuel consumption $(F C)$, it has also indirectly been the strongest driver of the corresponding GHG emissions.

Noise generated by commercial aircraft around airports, as one of the conditions for their certification, has been regulated at the local, national, and international level. Currently, all commercial aircraft meet the specified noise limits ${ }^{(5)}$.

As far as safety is concerned, the accident rate of commercial aircraft has generally been decreasing over time; for example, from $0.55 / 10^{6}$ flights in 1998 to $0.03 / 10^{6}$ flights in 2017 . Specifically, this rate with fatalities on the long-haul flights, carried out by the B777s and A330s aircraft between 1959 and 2016 was $0.20 / 10^{6}$ flights and $0.21 / 10^{6}$ flights, respectively. The most recent B787s, A350, and A380 have been without accidents with fatalities ${ }^{(6),(7)}$. 


\subsection{Commercial supersonic aircraft}

\subsubsection{Past developments}

Past development of commercial supersonic ${ }^{1}$ aircraft had materialised in the commercialisation of the two aircraft - the French/British Aerospatiale/BAC Concorde and the Soviet Union's TY 144. The Concorde entered commercial service in 1976 and retired in 2003. The TY 144 entered the commercial service in 1977 and retired in $1978^{(8)-(11)}$. Both aircraft had a similar design, technical productivity, operating costs, fuel consumption, related GHG emissions, and noise. However, regarding the latest four above-mentioned features, they had not fulfilled expectations of the main actors/stakeholders. The airfares had been based on the high operating costs, mainly influenced by the high fuel consumption. This had been additionally compromised by constraining the overland operations at the supersonic speed $(M>1)$ aimed at mitigating and/or avoiding excessive noise from the sonic boom(s). Under such circumstances, these aircraft had been inferior to their slower subsonic counterparts, the B 707 and the B 747, regarding the operational costs and consequently airfares ${ }^{(12)-(14)}$. Additionally, the accidents (crashes) of the Concorde (25 Jul 2000, Paris) and the TY 144 (3 June 1973, Paris Air Show) raised some concerns about their safety, which consequently speeded up their retirement $^{(15)}$.

\subsubsection{Past and current research and development}

After the retirement of the Concorde and the TY144, research and development of supersonic aircraft continued. One of the earliest efforts dealt with identifying the relevant research topics regarding the design, economic efficiency, and safety of these aircraft. This was initially elaborated by improving the existing and developing some innovative research techniques ${ }^{(27)}$. This was followed by elaborating the concepts of commercial supersonic transport aircraft in terms of identifying new research opportunities regarding critical technologies and areas needing continuous development. These included the airframe design, control systems, engines, and materials, as well as the issue of reducing the sonic boom, fuel consumption and GHG emission, improving in-flight safety, and the certification requirements ${ }^{(28,29)}$. Further research summarized the developments of the concepts of supersonic aircraft over the past 30 years, from the engineering, economic, and safety/environmental/social perspective ${ }^{(30)}$. This was certification by research on the possible introduction of $\mathrm{LH}_{2}$ as fuel for commercial air transportation. It elaborated the necessary conditions for smooth transition from conventional (Jet A) to new $\left(\mathrm{LH}_{2}\right)$ fuel, including the necessary modifications of the aircraft design. This resulted in the development of the concept of both subsonic and supersonic aircraft powered by $\mathrm{LH}_{2}{ }^{(20),(31)}$. In particular, comprehensive research on developing the concept of a large supersonic aircraft, including the overall long-term aspects related to the high-speed transport, was carried out. For example, two EC (European Commission) projects, LAPCAT and ATLLAS, developed the methodology for aircraft design including optimal integration of their airframe, engines, and materials. Additionally, some dedicated experiments were carried out to evaluate the overall feasibility of the proposed design under different operating conditions ${ }^{(24),(25)}$. RAMJET or SCRAMJET engines were also specifically explored as

${ }^{1}$ The current commercial aircraft operate at the subsonic speed of: $M<1.0$. The other relevant speeds in the given context are: i) Transonic $(0.8<M<1.3 ; 430-794 \mathrm{kt}$ or $980-1470 \mathrm{~km} / \mathrm{h})$; and ii) Supersonic $(1.3 \leq M \leq 5.0 ; 794-3308 \mathrm{kt}$ or $1470-6126 \mathrm{~km} / \mathrm{h})(4)$. 
propulsion systems for supersonic aircraft, including the challenges in their development, technical/technological and operational feasibility ${ }^{(32),(33)}$.

As far as the most recent endeavours of the airspace industry are concerned, Boeing has announced the development of a hypersonic aircraft with the cruising speed of about $M=5$. It is thought that it will be operational by the late $2030 \mathrm{~s}^{(34)}$. Additionally, three U.S.-based startup companies, Aerion, Spike, and Boom, are developing the new supersonic aircraft expected to be operational in the mid-2020s (see Table AI-1) ${ }^{(22),(23),(35)}$. The operational compatibility of the future supersonic aircraft has also been under scrutiny, with regard to the current and future ATC (air traffic control) system, and the corresponding flight operational rules and procedures. In particular, the prospective benefits and barriers to integrating these aircraft seamlessly in the U.S. NAS (National Airspace System) have been considered ${ }^{(12),(21),(39)}$.

Several research efforts have recently focused on the assessment of the potential market for the supersonic flights. One deals with the development of the air transport market, including its long-haul segment where the supersonic aircraft would most likely operate ${ }^{(36)}$. The other deals directly with the estimation of the global market potential for supersonic transportation by evaluating worldwide data on the premium ticket sales ${ }^{(37)}$.

One of the main concerns in developing the new concepts of supersonic aircraft has continued to be their economic efficiency. This has expected to be mainly influenced by the costs of substantial fuel consumption. The airfares based on such costs could make them eventually attractive primarily for business passengers with the presumably high value of their time. However, some research has indicated that if these aircraft were large and powered by $\mathrm{LH}_{2}$ fuel charged at the reasonable prices, their costs and related airfares would be quite competitive to those of their current subsonic counterparts ${ }^{(24)}$. Since the environmental and social impacts of supersonic aircraft powered by Jet-A fuel (kerosene) have expected to be substantial, the corresponding GHG emissions and their noise have been also under scrutiny. Some research has reviewed the environmental issues and challenges of relevance to the design of supersonic business jets. Due to the inherent interrelation of the above-mentioned performance, a multidisciplinary design, analysis and optimisation have been considered as necessary for creating "low-boom" "low-drag" supersonic aircraft ${ }^{(38)}$. Additionally, a preliminary assessment of noise and GHG emissions by supersonic aircraft has indicated that their most likely design would not enable fulfilment of the current (2018/19) global standards for GHG emission of and local-airport noise. Particularly, according to the operating scenarios on the selected routes, their average fuel consumption and related GNG emissions (per passenger) would exceed those of their current subsonic counterparts several fold ${ }^{(18)}$. Also, the regulation of operations of the new supersonic aircraft, which is already underway, is primarily related to the sonic boom currently restricting their overland operation. One of these has been the U.S. FAA (Federal Aviation Administration) initiative for creating federal and international policies, regulations, and standards to certify the safe and efficient operation of civil supersonic aircraft ${ }^{(12),(19),(39)}$.

The above-mentioned concepts of supersonic aircraft have been thought to carry out the long-haul flights with a rather positive balance between their effects and impacts. The effects have included travel speed, technical productivity, and economics. The impacts have included fuel consumption, GHG emissions, and noise. Some of these thoughts have also been systematically articulated as far-term (beyond the year 2035) research objectives of the two of the six strategic thrusts of the U.S. NASA strategic research program. The two relevant strategic thrusts have been "Innovation in Commercial Supersonic Aircraft" and "Transition to Alternative Propulsion and Energy"(16). Consequently, the general requirements for design and operation of these aircraft have been as follows ${ }^{(4),(8),(16)-(23)}$ : 
- Sufficient range for operating along the current and future long-haul, including the longest-haul non-stop routes;

- Flight costs and related air fares comparable to those of their subsonic counterparts and consequently attractive for both airlines and different categories of air passengers (low, medium, high income; business, leisure);

- Fuel consumption and related GHG emissions at the level at least neutral compared to their current subsonic counterparts; and

- Noise around airports and the sonic boom overland within the existing and forthcoming regulatory limits, the former similar to their subsonic counterparts.

The causal (regression) relationship between the technical productivity (TP), cruising speed (v), and capacity $(S)$ of the past and current concepts of supersonic aircraft is estimated as follows (based on data in Table AI-1 (Appendix I)):

$$
\begin{aligned}
& T P(S, v)=-308.004+0.959 \cdot S+0.307 \cdot v \\
& t(-10.575)(6.442)(10.467) \\
& R^{2}=0.987 ; F=296.077 ; D W=1.553 ; N=10 \quad(12<S<300 ; 860<v<2867 \mathrm{kt}) \ldots(2)
\end{aligned}
$$

As can be seen, the aircraft capacity $(S)$ and cruising speed (v) have very strongly influenced on technical productivity $(T P)$. Again, this influence is about three times greater thanks to the seat capacity (coefficient at the variable $(S)$ ) than thanks to the maximum speed (coefficient at the variable $(v)$ ). Additionally, the influence of speed on the technical productivity $(T P)$ is for more than four times greater than in the case of subsonic aircraft (see Eq. 1a).

In regard to economics, some estimates indicate that the price of currently developing Boom Aircraft will be about 200. $10^{6}$ \$US and that of the previous EC LAPCAT Hydrogen Mach 5 Cruiser A2 $640 \cdot 10^{6} €$. Based on the advertised prices on particular long-haul routes, the average operating cost of Boom Aircraft could be less than about $1.5-1.8 \mathrm{e} / \mathrm{s}-$ $\mathrm{nm}$ and that of the EC Hydrogen Mach 5 Cruiser A2 about $6.2 \mathrm{~d} / \mathrm{s}-\mathrm{nm}$ (s-nm - seat-nautical mile) $)^{(18),(22),(24),(25)}$. The fuel consumption, GHG emissions, and noise of these aircraft are expected to be in line with the above-mentioned requirements. In particular, the noise from the sonic boom is expected to be reduced to the level of about $70-80 \mathrm{~dB}$ primarily through aircraft design and the increase in their cruising altitude, both of which could eventually allow for unrestricted overland operations ${ }^{(22)}$.

\subsection{MODELLING PERFORMANCE OF AN AIR ROUTE NETWORK}

\subsection{Objectives}

The above-mentioned overview has indicated the existence of long-standing research efforts to develop the concepts of supersonic aircraft. However, those dealing with the systematic analysing, modelling, and comparing performance with those of the subsonic aircraft have been fragmentary or non-existent. This especially applies to the consideration of different operating scenarios including competition or eventually full replacement in the given (mainly long-haul) air route networks. Therefore, the objectives of this paper are to partially decrease this fragmentation and mainly increase interest in the topic within the academic community. 


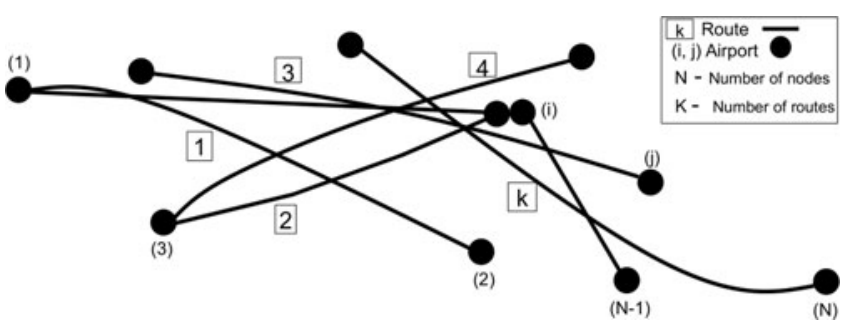

Figure 1. Simplified scheme of a long-haul air route network.

As such, the paper provides a framework for the systematic examination of the performance of a given long-haul air route network, exclusively operated by the prospectively forthcoming supersonic aircraft and their subsonic counterparts, according to the "what-if" scenario. This includes definition of the indicators of the above-mentioned network performance, development of their analytical models, and application of the models to the selected network case.

\subsection{Assumptions}

The models of performance indicators of the given air route network are based on the following assumptions reflecting the "what-if" operating scenarios:

- The air route network has a point-to-point spatial configuration consisting of airports as the O-D (origin-destination) nodes of aircraft/flights and their passengers, the long-haul air routes ${ }^{2}$ as the network links as shown in Fig. 1;

- The characteristics of both subsonic and supersonic aircraft/flights are considered in modelling the particular indicators;

- The supersonic aircraft are fully operational including sufficiently (long) range for flying non-stop on all routes of the network;

- The airlines operate either a fleet of subsonic aircraft powered by Jet A or a fleet of supersonic aircraft powered by $\mathrm{LH}_{2}$ (Liquid Hydrogen) fuel; both fleets are homogenous, i.e. $\mathrm{n}$ consist of the same aircraft types;

- The profiles of subsonic flights continue to be as at present both around the airports (following the SIDs (standard instrument departure) routes and STARs (standard terminal arrival route(s)), and en-route (4D RNAV trajectories). The profiles of supersonic flights need to be standardised. This implies that the ATC (air traffic control) would assign the aircraft dedicated three-dimensional (airspace) corridors mainly separated from the subsonic traffic. These would enable: i) taking-off from the origin airport and proceeding along the dedicated SIDs through the terminal area of the origin airport; ii) leaving the terminal area, climbing up to the cruising altitude while accelerating to the supersonic cruising speed; iii) cruising with the constant supersonic speed on the constant cruising altitude; iv) ending cruising and descending from the cruising altitude, while decelerating to the entry speed of the terminal area of the destination airport; v) entering the terminal area and proceeding along the dedicated STARs, again separated from the

${ }^{2}$ The long-haul non-stop routes are considered to be those with the length from 6000 to $8000 \mathrm{~nm}$ (nm - nautical mile; $1 \mathrm{~nm}=1.852 \mathrm{~km})$. 


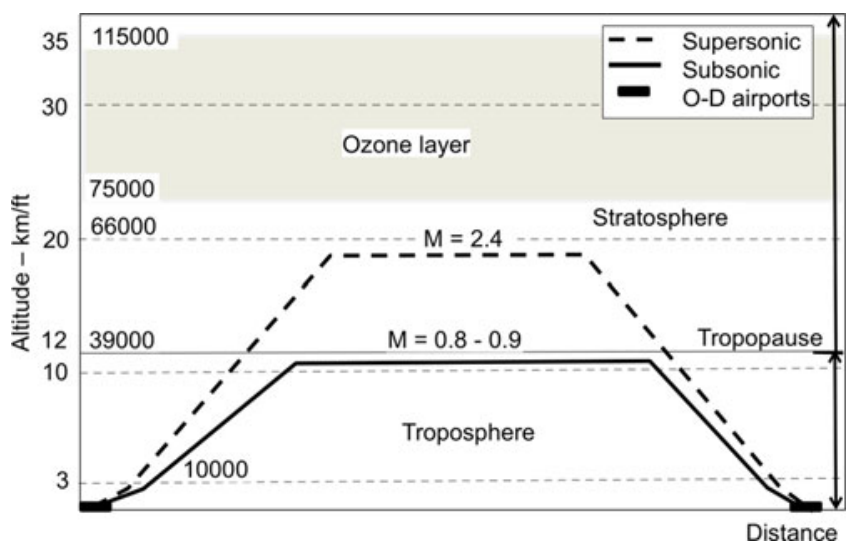

Figure 2. Simplified scheme of the vertical profile of subsonic and supersonic flight(s).

subsonic arriving traffic; and vi) entering the final approach path and landing. During take-off and landing, these aircraft are considered as in the heavy (or super heavy) wakevortex category. Ideally these aircraft could share the SIDs and STARs of their subsonic counterparts within the corresponding noise constraints ${ }^{(12),(39)}$; a simplified scheme of the vertical profile of both categories of flights is shown in Fig. 2.

- A single airline or several airlines and/or their alliances operate in the network. Their market relationships, such as collaboration or competition, are not considered. The number of scheduled flights and their load factors on each network route are the same; this implies equality/uniformity of the O-D passenger demand accommodated by these flights under the given conditions.

- The direct fuel consumption and related GHG emissions of both categories of aircraft/flights are considered only.

- The GHG from burning particular fuels (Jet A and $\mathrm{LH}_{2}$ ) are assumed to impact the environment independently, i.e. without interrelating with each other ${ }^{(40)}$.

- The airport airside infrastructure (runways, taxiways, and apron/gate complex) is assumed to be suitable for accommodating supersonic aircraft safely, effectively, and efficiently; in general some modifications of the apron/gate parking stands and provision of $\mathrm{LH}_{2}$ fuel delivery would be needed.

\subsection{The models of performance indicators}

The analytical models of performance indicators for the air route network shown in Fig. 1 are developed for its representative (average) route. As such, they can be applied to each network route and estimated in both absolute and relative terms. The corresponding values for the entire network can be obtained by adding up these estimated values for all routes. The models of indicators of infrastructural and technical/technological performance are assumed to be implicitly given and therefore not modelled.

\subsubsection{Indicators of operational performance}

The operational performance indicators are passenger demand, flight frequency on a route and network aircraft turnaround time on a route, transport work, technical productivity, and the size of the aircraft fleet. 
Passenger demand and flight frequency on a route: The passenger demand on a network route $(k)$ in the single direction, served by either category of aircraft during time $(\Delta \tau)$, is assumed to be $\left(Q_{k}(\Delta \tau)\right)^{(37)}$. The flight frequency by either aircraft category to accommodate this demand can be estimated as follows ${ }^{(13)}$ :

$$
f_{k}(\Delta \tau)=Q_{k}(\Delta \tau) /\left(\lambda_{k} \cdot S_{k}\right)
$$

$k \quad$ route in the given network $(k=1,2, \ldots, K)$;

$\Delta \tau \quad$ time interval in which the flights by either aircraft category are scheduled on route (k) (h, day, year);

$\lambda_{k}, S_{k} \quad$ average aircraft load factor and capacity, respectively, of a flight on route $(k)$ carried out by either aircraft category $\left(\lambda_{k} \leq 1.0\right)(-;$ seats/dep);

$K \quad$ number of routes in the network.

Aircraft turnaround time on a route: The turnaround time of an aircraft of either category on route $(k)$ is expressed as follows:

$$
\tau_{k}\left(R_{k}\right)=t_{0 / k / 1}+t_{k}\left(R_{k / 1}\right)+t_{0 / k / 2}+t_{k}\left(D R_{k / 2}\right)
$$

$R_{k / 1}, R_{k / 2} \quad$ length of route $(k)$ in direction (1) and (2), respectively (nm, $\mathrm{km}$ );

$t_{k}\left(R_{k / 1}\right), t_{k}\left(R_{k / 2}\right)$ flight time by aircraft category (i) in the direction (1) and (2), respectively, on route $(k),(\mathrm{h})$;

$t_{0 / k / 1}, t_{0 / k / 2} \quad$ handling time of an aircraft of either category at the apron/gate complex of the end airports, before operating on route $(k)$ in direction (1) and (2), respectively, (h).

The time $\left(t_{k}\left(R_{k / 1}\right)\right)$ or $\left(t_{k}\left(R_{k / 2}\right)\right)$ in Eq.3b is approximated as follows:

$$
t_{k}\left(R_{k / .}\right)=t_{k / c l / .}+t_{k / c r / .}+t_{k / d e / .}+1 / 2 \cdot t_{k / L T O}
$$

$t_{k / c l}$. climbing time of a flight of either category operating on route $(k)$ in the given direction $(\min )$;

$t_{k / c r}$. cruising time of a flight of either category operating on route $(k)$ in the given direction (min);

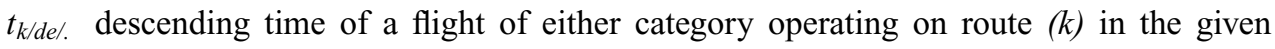
direction ( $\mathrm{min})$;

$t_{k / L T O}$ LTO (Landing and Take-Off) ${ }^{3}$ cycle of a flight of either category before and after operating on route $(k)(\min )(i=1,2)$.

The other symbols are analogous to those in the previous equations.

The detailed analytical models for estimating the flight time components in Eq. $3 \mathrm{c}$ are given in Appendix II.

${ }^{3}$ This includes the taxing-out and take-off time at the origin and the landing and taxing-in time at the destination airport ${ }^{(41)}$. 
Transport work, technical productivity, and size of the aircraft fleet: The transport work of the flight carried out on route $(k)$ of the network by either category of aircraft during time $(\Delta \tau)$ is estimated as follows:

$$
T W_{k}(\Delta \tau)=f_{k}(\Delta \tau) \cdot R_{k} \cdot \lambda_{k} \cdot S_{k}
$$

where all symbols are analogous to those in the previous equations.

The technical productivity of the flight carried out on route $(k)$ of the network by either category of aircraft during time $(\Delta \tau)$ is estimated as follows:

$$
T P_{k}(\Delta \tau)=f_{k}(\Delta \tau) \cdot \lambda_{k} \cdot S_{k} \cdot \bar{v}_{k}\left(R_{k}\right)
$$

$\bar{v}_{k}\left(R_{k}\right)$ average flight speed carried out by either aircraft category on route $\left(R_{k}\right)$ in both directions (1) and (2) $(\mathrm{km} / \mathrm{h}$ or $\mathrm{kt})$.

From Eq. 3 c, the average speed $\bar{v}_{k}\left(R_{k}\right)$ in Eq. 3e is expressed as follows:

$$
\bar{v}_{k}\left(R_{k}\right)=R_{k} / \tau_{k}\left(R_{k}\right)
$$

From Eq. 3a and 3b, the required fleet of either aircraft category to serve the network under given conditions is expressed as follows:

$$
n(\Delta \tau)=\sum_{k=1}^{K} f_{k}(\Delta \tau) \cdot \tau_{k}\left(R_{k}\right)
$$

The other symbols are analogous to those in the previous equations.

\subsubsection{Indicators of economic performance}

The indicators of economic performance are flight cost, cost of passenger time, and contribution to GDP (gross domestic product).

Flight cost: The total cost of a single flight carried out by either category of aircraft on route $(k)$ of the network can be estimated as follows:

$$
C_{k / T}=C_{k / F}+C_{k / o}
$$

where

$C_{k / F}$ fixed cost of a flight carried out on route $(k)$ (\$US/flight);

$C_{k / o}$ is the variable, i.e., operating cost of a flight carried out on route ( $k$ ) (\$US/flight).

The fixed cost $\left(C_{k / F)}\right.$ in Eq. 4a can be estimated as follows ${ }^{(42)}$ :

$$
C_{k / F}=\left(\frac{P \cdot A D R}{\sum_{k=1}^{K} f_{k}(U L)}\right)=\left[\frac{P \cdot(100-R V / U L)}{\sum_{k=1}^{K} f_{k}(U L)}\right]
$$


$P \quad$ aircraft price including the capital maintenance costs during its useful life (\$US/aircraft);

$A D R \quad$ aircraft annual depreciation rate $(\%)$;

$R V \quad$ aircraft residual value (\%);

$U L \quad$ aircraft useful life (years);

$f_{k}(U L)$ number of flights carried out on network route $(k)$ during the aircraft's useful life.

The other symbols are analogous to those in Eq. 3a.

The operating cost $\left(C_{k / o}\right)$ in Eq. $4 \mathrm{a}$ includes the cost of fuel, crew, maintenance, insurance, fees (airport, ATC), and others (www.PlaneStats.com). For the flights carried out by the subsonic aircraft this cost is usually estimated by the empirical data. For the flights carried out by the supersonic aircraft, this cost can be approximated by using the corresponding available data in combination with an analogy with the cost of their subsonic counterparts ${ }^{(24)}$. From Eq. $4 \mathrm{a}$, the average cost is expressed as follows:

$$
\bar{C}_{k}=\frac{C_{k / T}}{R_{k} \cdot \lambda_{k} \cdot S_{k}}=\frac{C_{k / F}+C_{k / o}}{R_{k} \cdot \lambda_{k} \cdot S_{k}}
$$

$\bar{c}_{k} \quad$ average cost of a flight carried out on route $(k)$ of the network (\$US/p-km).

The other symbols are analogous to those in the previous equations.

As mentioned above, in combination with the route length, the average cost $\left(\bar{c}_{k}\right)$ in Eq. $4 \mathrm{c}$ can be considered as the basis for setting up the airfares.

Cost of passenger time: Using supersonic instead of subsonic flights is expected to bring savings in the passenger time and related costs. These average savings by a flight of either category carried out on route $(k)$ can be estimated as follows:

$$
\bar{c}_{k / s v}=\left[\alpha_{k} \cdot\left(t_{k / 1}^{*}-t_{k / 2}^{*}\right)\right] /\left(R_{k} \cdot \lambda_{k} \cdot S_{k}\right)
$$

$\mathrm{t}_{\mathrm{k} / 1}^{*} \mathrm{t}_{\mathrm{k} / 2}^{*}$ flight time on route $(k)$ by subsonic $(i=1)$ and supersonic $(i=2)$ aircraft, respectively, (h) $\left(\mathrm{t}_{\mathrm{k} / 1}^{*}>\mathrm{t}_{\mathrm{k} / 2}^{*}\right)$;

$\alpha_{k} \quad$ average value of time of a user/passenger travelling on route $(k)(\$ U S / h-p)$.

The other symbols are analogous to those in the previous equations.

Contribution to GDP: The average contribution of the subsonic or supersonic flight(s) carried out in the network to the GDP is estimated as follows:

$$
\bar{r}_{G D P}=\left(G D P / V_{R P K}\right)
$$

$\bar{r}_{G D P}$ average GDP generated by commercial air transportation in the given region (\$US/p$\mathrm{km})$;

GDP total GDP generated by commercial air transportation in the given region during the specified period of time (\$US/year);

$V_{R P K}$ output of commercial air transportation in the given region during the specified period of time (RPK/year) (RPK - revenue passenger kilometre).

Overall social-economic feasibility: The overall social-economic feasibility of the subsonic or supersonic flight(s) carried out on route $(k)$ of the network is estimated as the 
difference between its total cost and contribution to GDP. From Eq. 4 (c, d, e) and $5 \mathrm{~d}$ (see below) this equals:

$$
\Delta c_{k}=\bar{r}_{G D P}-\left(\bar{c}_{k}+\bar{c}_{k / s v}+\bar{c}_{k / e}\right)
$$

$\bar{c}_{\mathrm{k} / \mathrm{e}}$ average cost of GHG emissions of a flight carried out on route $(k)$ of the network (\$US/p-km).

The other symbols are analogous to those in the previous equations.

If $\left(\Delta c_{k}\right)$ is positive, the flight on the route $(k)$ is overall social-economically feasible, and vice versa.

\subsubsection{Indicators of environmental performance}

The indicators of environmental performance are fuel consumption, emissions of GHG, and contribution to the global warming and climate change.

Fuel consumption: The fuel consumption of subsonic flights in the network is estimated by using the available empirical data. That of the supersonic flights is estimated by the analytical models considering the mechanical forces acting on the aircraft during the particular phases of flight - climb, cruise, and descend - and the corresponding energy consumption. The summed quantity is then increased for the factor including the fuel consumed during the LTO cycle(s). In general, in each of the above-mentioned flight phases the fuel consumption is estimated as follows:

$$
F C=[(1 / \eta) \cdot T \cdot r] / e_{f}
$$

$T \quad$ thrust force during the given phase of flight (N) (N - Newton);

$r \quad$ distance along which the thrust force $(T)$ is applied $(\mathrm{m}, \mathrm{km}, \mathrm{nm})$;

$e_{f} \quad$ specific energy of the fuel used $(\mathrm{J} / \mathrm{kg})(\mathrm{J}-\mathrm{Joule})$;

$\eta \quad$ propulsion efficiency of the aircraft engines during the given phase of flight $\left(\eta_{t o}<1.0\right)$.

After expanding Eq. 5a in Appendix III for the particular flight phases - climbing ( $\mathrm{cl}$ ), cruising ( $c r)$, descending (de), and (LTO) cycle, the total fuel consumption of a flight carried out by supersonic aircraft on route $(k)$ of the network can be estimated as follows:

$$
F C_{k}=F C_{k / c l}+F C_{k / c r}+F C_{k / d e}+(1 / 2) \cdot F C_{k / L T O}
$$

GHG emissions: GHG emissions by subsonic aircraft can be estimated by using available empirical data. Based on Eq. 5b, the GHG emissions by both subsonic and supersonic flight are estimated as follows:

$$
E M_{k}=F C_{k} \cdot \sum_{m=1}^{M} e_{m}
$$

$F C_{k}$ fuel consumption by a flight carried out on route $(k)$ by either category of aircraft $(\mathrm{kg}$, ton);

$e_{m} \quad$ emission rate of the $(m)$-th GHG from burning the given type of fuel ( $\mathrm{kg}$ or ton of $\mathrm{GHG} / \mathrm{kg}$ or ton of fuel); 


\section{$M \quad$ number of different GHG emitted by burning the given type of fuel.}

If internalised, the total and average cost of GHG emissions of a flight carried out on route (k) by either category of aircraft can be estimated as follows:

$$
C_{k / e}=F C_{k} \cdot \sum_{m=1}^{M} c_{e / m} \cdot e_{m} \quad \text { and } \quad \bar{c}_{k / e}=\frac{C_{k / e}}{R_{k} \cdot \lambda_{k} \cdot S_{k}}
$$

$c_{e / m}$ unit charge of the (m)-th GHG (\$US/kg, \$US/ton).

The other symbols are analogous to those in the previous equations.

Contribution to global warming and climate change: The GHG emitted by subsonic or supersonic flight powered by either type of fuel (Jet A or $\mathrm{LH}_{2}$ ) contribute to global warming and climate change. Each GHG has its GWP (global warming potential) estimated for the future long-term period (for example, 100 years ahead) ${ }^{(43),(44)}$. Based on Eq. 5c, the GWP of any subsonic or supersonic flight carried out on route $(k)$ can be estimated as follows (tons of GHG/flight):

$$
G W P_{k}=E M_{k} \cdot \sum_{m=1}^{M} G W P_{m}
$$

$G W P_{m}$ Global Warming Potential of the (m)-th GHG (-).

The other symbols are analogous to those in the previous equations.

The relative savings in GWP by carrying out the supersonic $\left(i=2-\mathrm{LH}_{2}\right.$ fuel) instead of the subsonic ( $i=1$ - Jet A fuel) flight(s) on route $(k)$ of the network are estimated as follows:

$$
\Delta G W P(k)=\left(1-\frac{G W P(k, 2)}{G W P(k, 1)}\right) \cdot 100
$$

All symbols are analogous to those in the previous equations.

\subsubsection{Indicators of social performance}

The indicators of social performance are noise, congestion and delays, and safety.

Noise: The noise produced by the subsonic aircraft around airports has been permanently regulated and used as the criteria for their (noise) certification ${ }^{(5)}$. The noise by the forthcoming supersonic aircraft, in addition to that around airports, has been and will continue to be the subject to specific regulation along the (overland) segments of air routes due to the sonic boom $^{(12),(39)}$. This noise by a supersonic flight passing above an observer on the ground can be estimated as follows ${ }^{(45)}$ :

$$
L_{2}=L_{1}-20 \cdot \log d_{1} / d_{2}
$$

$L_{1}, L_{2} \quad$ noise at the reference distance $\left(d_{1}\right)$ and at the distance $\left(d_{2}\right)$ of an observer on the ground from the noise source, i.e. the flying over aircraft, respectively $(\mathrm{dBA})\left(d_{l}\right.$, $\left.d_{2}-\mathrm{nm}, \mathrm{km}\right)$. 
The distance $\left(d_{l}\right)$ is very close to the noise source, i.e. the flying over aircraft. The distance $\left(d_{2}\right)$ is estimated as follows ${ }^{(11)}$ :

$$
d_{2}=H / \sin \theta \quad \text { and } \quad \theta=\sin ^{-1}(1 / M)
$$

$H \quad$ altitude of supersonic flight (m, ft);

$\theta \quad$ Mach angle $\left(^{\circ}\right)$;

$M \quad$ Mach number $(M>1)$.

At present, the costs of noise as an externality by supersonic aircraft are quite uncertain and are therefore not elaborated in the given context.

Congestion, delays and safety: Both categories of flights are carried out under the equivalent operational conditions at all airports of the network. As mentioned above, they are assumed to be "ultimately" free from the substantial congestion and delays. The same applies to their safety, i.e. the risk of and actual occurrence of the air traffic incidents/accidents. Therefore, the corresponding indicators of this performance and related costs/externalities are not elaborated.

\subsection{AN APPLICATION OF MODELS OF PERFORMANCE INDICATORS}

\subsection{Inputs}

The indicators of particular performance of a given air route network are estimated by two categories of data: real-life input data on subsonic flights and hypothetical input data on "what-if" scenario-based supersonic flights. In both cases adjustments are made to reflect operations of the network and flights in the year 2050. This is assumed to be the year that supersonic flights will be launched. The input data is also categorised in regard to the particular performance.

\subsubsection{Infrastructural performance}

The indicators of infrastructural performance are represented by the characteristics of the existing air route network shown in Fig. 3 and given in Table 1.

The same network is assumed to be operated exclusively either by the above-mentioned subsonic aircraft or their supersonic counterparts in the year 2050.

\subsubsection{Technical/technological performance}

The fleet of subsonic aircraft contains the average aircraft type based on Eq. 1 (a, b, c). The simplified layout of considered supersonic aircraft is shown in Fig. 4 (the EC's LAPCAT Hydrogen Mach 5 A2 concept) ${ }^{(24),(25),(32) . ~}$

Additionally, the design-related characteristics of an average subsonic and supersonic aircraft belonging to the corresponding fleets are given in Table 2. On the one hand, these characteristics can be considered as inputs; on the other, they can represent indicators of technical/technological performance of the network and flights.

\subsubsection{Operational performance}

The inputs for estimating the indicators of operational performance of the network are synthesised from the relevant empirical data (subsonic flights) and the hypothetical "what-if" operational scenario-based data (supersonic flights) given in Table 1 and 2. 


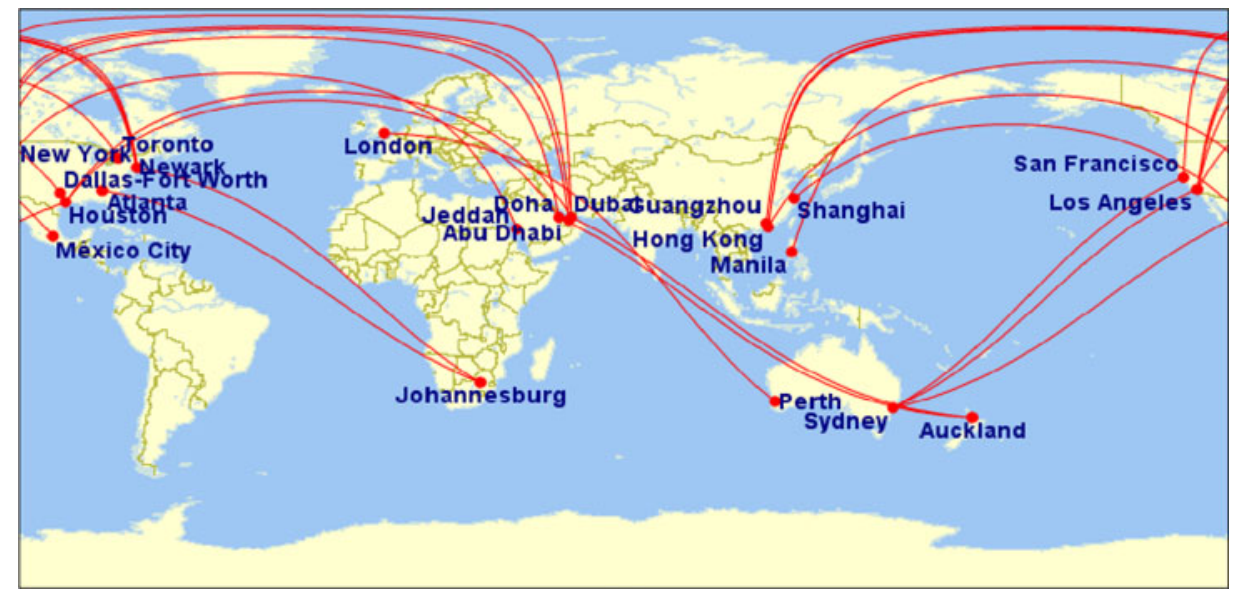

Figure 3. Simplified geographical scheme of the air route network consisting of 25 world's longest routes in the given example (period: the year 2018) ${ }^{(65)}$.

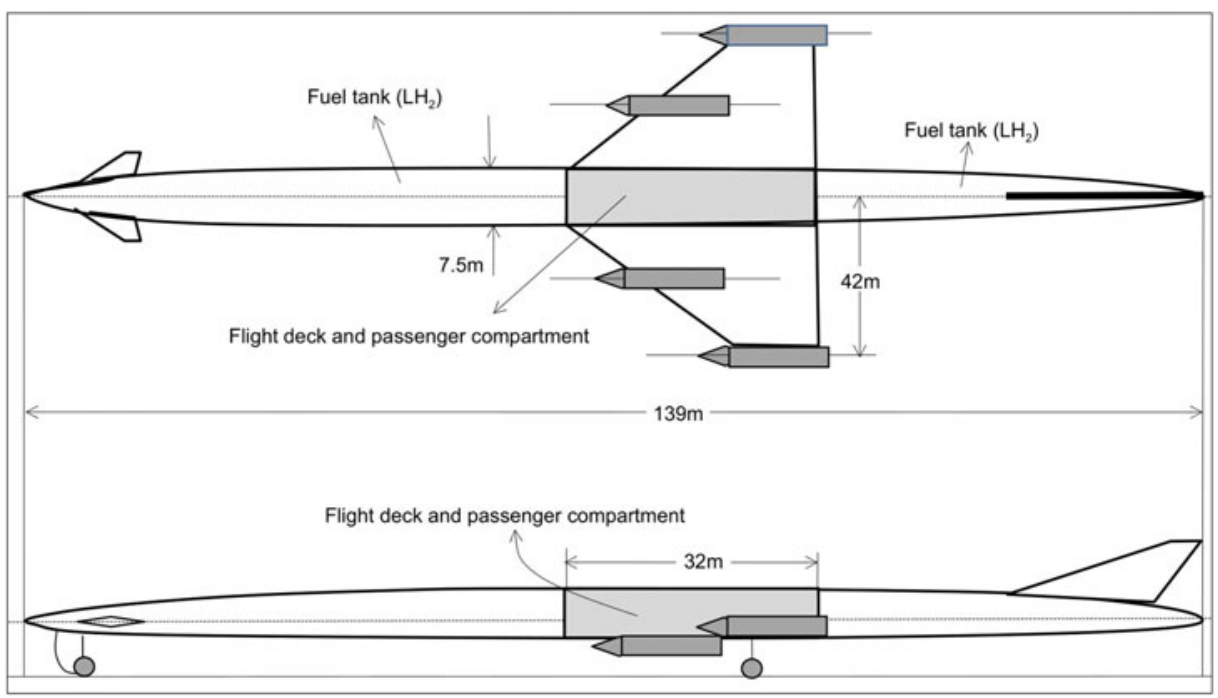

Figure 4. Simplified layout of supersonic aircraft in the given example (LAPCAT Hydrogen Mach 5 A2 concept) (24), (25).

\subsubsection{Economic performance}

Flight cost: The inputs for estimating the total operating cost of subsonic flight(s) are derived from Eq. 1b. The inputs for estimating the total operating cost of supersonic flight(s) operated at the speed $M=2.4$ are derived as follows.

The price of a supersonic aircraft including the capital maintenance cost during the lifecycle is assumed to be: $P=450 \cdot 10^{6} \$$ US. This is similar to that of the A380 aircraft ${ }^{(46),(47)}$. The aircraft residual value at the end of useful life of: $U L=20$ years is assumed to be: $R V=10 \%$, which gives $A D R$ (Annual Depreciation Rate): $=4.5 \% /$ year $^{(42)}$. The inputs for estimating the variable cost component are as follows: the fuel cost - 1.00 and $0.85 \$ \mathrm{US} / \mathrm{kg}$ of 


\section{Table 1}

Characteristics of the existing long-haul air route network and subsonic non-stop flights in the given example (Fig. 2) (Period: the year 2018) ${ }^{(65)}$ )

No.

\section{1}

2

3

4

5

6

7

8

9

10

11

12

13

14

15

16

17

18

19

20

21

22

23

24

25

Route
Auckland - Doha
Perth - London Heathrow
Auckland - Dubai
Los Angeles - Singapore
Houston - Sydney
Dallas/Ft. Worth - Sydney
San Francisco - Singapore
San Francisco - Singapore
Johannesburg - Atlanta
Abu Dhabi - Los Angeles
Dubai - Los Angeles
Jeddah - Los Angeles
Doha - Los Angeles
Manila - Toronto
Dubai - Houston
Dallas/Ft. Worth - Hong Kong
Dubai - San Francisco
Hong Kong - New York JFK
Hong Kong - Newark EWR
Hong Kong - Newark EWR
Doha - Houston
Dubai - Dallas/Ft. Worth
Shanghai - Mexico City
Guangzhou - New York JFK
Johannesburg - New York JFK

Average:
Route Length Flight Time

$R(\mathrm{~nm}) \quad t(R)(h: m i n) \quad$ Aircraft Type

$7853 \quad 17: 17 \quad$ Boeing 777-200LR

$7837 \quad 17: 20$

$7672 \quad 16: 34$

$7620 \quad 17: 21$

$7460 \quad 17: 07$

$7445 \quad 16: 47$

$7333 \quad 16: 57$

$7338 \quad 16: 46$

$7327 \quad 16: 04$

$7285 \quad 16: 08$

7241

7235

7212

7139

6622

7057

7023

6992

6994

6994

6523

6983

6973

6962

6936

6532
Boeing 787-9

Airbus A380-800

Boeing 787-9

Boeing 787-9

Airbus A380-800

Airbus A350-900

Boeing 787-9

Boeing 777-200LR

Boeing 777-300ER

Airbus A380-800

Boeing 777-300

$16: 11$

$15: 55$

$16: 27$

$15: 48$

16:08

15:05

$15: 18$

$15: 18$

$15: 21$

$15: 54$

$15: 26$

$16: 55$

$15: 25$

$15: 33$

16:00
Boeing 777-200LR

Boeing 777-300

Boeing 777-300ER

Boeing 777-300ER

Airbus A380-800

Boeing 777-300ER

Airbus A350-900

Boeing 777-200ER

Boeing 777-200LR

Boeing 777-300ER

Boeing 787-8

Boeing 777-300ER

Airbus A340-600

$\mathrm{LH}_{2}{ }^{(48)}$; the crew cost - 2000 \$US/h. The fixed, fuel, and crew costs are assumed to account for $70 \%$ of the total operating cost ${ }^{(49)}$. The inputs for both subsonic and supersonic flights are adjusted to the prospective conditions in the year 2050 .

Cost of passenger time: The inputs for estimating the prospective savings in the cost of passenger time if using supersonic instead subsonic flights are represented by the average value of passenger time of: $\alpha_{k}=74 \$ \mathrm{US} / \mathrm{h}-\mathrm{p}$. Based on 50\% medium and 50\% high income passengers, both performing $50 \%$ business and $50 \%$ leisure trips. This value is assumed to be also relevant in the year 2050 ( $\mathrm{h}$ - hour; $\mathrm{p}$ - passenger) ${ }^{(50),(51)}$.

Contribution to GDP: The inputs for estimating the average contribution of commercial air transportation to GDP are obtained from the long-term annual forecasts for global commercial air passenger transportation and its contribution to $\mathrm{GDP}^{(52)}$. For the year 2050, $G D P_{2050}=5.4 \cdot 10^{12} \$ \mathrm{US} /$ year and $V_{R P K / 2050}=14.1 \cdot 10^{12} \mathrm{RPK} /$ year, which gives: $\bar{r}_{G D P / 2050}$ $=\left(G D P / V_{R P K}\right)_{2050}=5.59 \cdot 10^{12} \$ \mathrm{US} / 14.1 \cdot 10^{12} \mathrm{RPK}=0.3965 \$ \mathrm{US} / \mathrm{p}-\mathrm{km}$. 
Table 2

Some design characteristics of subsonic and supersonic aircraft in the given example (24), (28), (32)

\section{Design Characteristics}

\begin{tabular}{|c|c|c|}
\hline \multirow[t]{2}{*}{ Design Characteristics } & \multicolumn{2}{|c|}{ Aircraft Category } \\
\hline & $\begin{array}{c}\text { Subsonic }^{\mathrm{a}} \\
\mathbf{M}<\mathbf{1 . 0}\end{array}$ & $\begin{array}{c}\text { Supersonic }^{\mathrm{b}} \\
\mathbf{M}=\mathbf{2 . 4}\end{array}$ \\
\hline Length (m) & 69.00 & 139 \\
\hline Wing span (m) & 64.32 & 42 \\
\hline Wing aspect ratio & 9.19 & 1.87 \\
\hline L/D (lift-to-drag) ratio (max) & 17.77 & $8.8^{\mathrm{c}}$ \\
\hline Take-off weight (tons) & 289 & 400 \\
\hline Number of engines (-) & 2 & 4 \\
\hline Take-off speed (kt) & 160 & 185 \\
\hline Cruising speed (Mach) & 0.87 & 2.4 \\
\hline Landing speed (kt) & 145 & 175 \\
\hline Capacity (seats) & 300 & 300 \\
\hline Load factor (-) & 0.70 & 0.70 \\
\hline
\end{tabular}

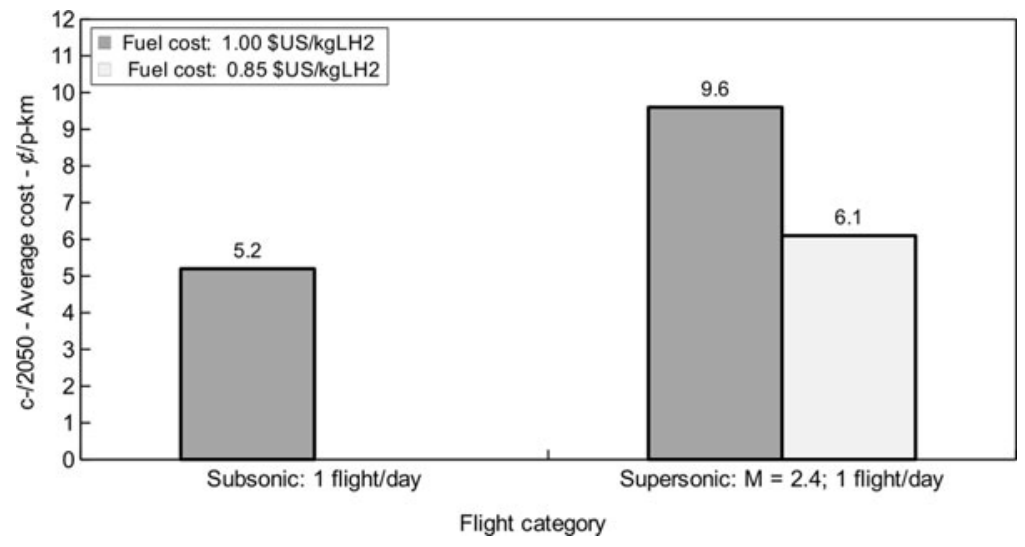

Figure 5. Indicators of economic performance: The average operating cost of particular categories of flights carried out on an average route of the network in the given example (period: the year 2050).

\subsubsection{Environmental performance}

Fuel consumption: The regression equation in Eq. 1c and the inputs in Table 2 are used for estimating the fuel consumption of subsonic flight(s). The inputs in Table 2, 3, and 4 are used in the corresponding models (Appendix III) to estimate the fuel consumption of the supersonic flight(s). 


\section{Table 3}

\section{Characteristics of supersonic flight(s) in the given example}

\section{Phase of Flight}

Climb

Altitude $(H)\left(10^{3}\right.$ feet $)$

Climb angle $\left(\beta_{c l}\right)\left({ }^{0}\right)$

Flying speed $(v)(\mathrm{kt})^{\mathrm{a}}$

Average rate of climb $(R / C)(\mathrm{ft} / \mathrm{min})^{\mathrm{b}}$

Average speed $\left(\bar{v}_{c l}\right)(\mathrm{m} / \mathrm{s})$

Avg. longitudinal acceleration $\left(a_{c l}{ }^{+}\right)\left(\mathrm{m} / \mathrm{s}^{2}\right)$

Distance $\left(r_{c l}\right)(\mathrm{km}, \mathrm{nm})$

Time $\left(t_{c l}\right)(\mathrm{min})^{\mathrm{c}}$

Propulsion efficiency $\left(\eta_{c l}\right)(-)$

Coeff. of the aerodynamic drag: $C_{d / c l}\left(\bar{v}_{c l}\right)(-)^{\mathrm{d}}$

Average air density $\left(\bar{\rho}_{c l}\right)\left(\mathrm{kg} / \mathrm{m}^{3}\right)$

Cruise

Altitude $(H)\left(10^{3}\right.$ feet $)$

Air density $\left(\rho_{c r}\right)\left(\mathrm{kg} / \mathrm{m}^{3}\right)^{\mathrm{e}}$

Coeff. of parasite drag at zero lift $\left(C_{D 0)}{ }^{\mathrm{f}}\right.$

Flying speed $(v)(\mathrm{m} / \mathrm{s})$

Effective aircraft length $(l)(\mathrm{m})^{\mathrm{g}}$

Wingspan (b) (m)

Radius of the aircraft fuselage $(r)(\mathrm{m})^{\mathrm{g}}$

Total volume $(\mathrm{Vol})\left(\mathrm{m}^{3}\right)^{\mathrm{g}}$

Dynamic pressure $(q)\left(\mathrm{N} / \mathrm{m}^{2}\right)$

Distance $\left(r_{c r}\right)(\mathrm{km} ; \mathrm{nm})$

Time $\left(t_{c r}\right)(\mathrm{h})$

Propulsion efficiency $\left(\eta_{c r}\right)(-)^{g}$

Descend

Altitude $(H)\left(10^{3}\right.$ feet $)$

Descend angle $\left(\beta_{d e)}\left({ }^{0}\right)\right.$

Flying speed $(v)(\mathrm{kt})^{\mathrm{a}}$

Average rate of descend $(R / D)(\mathrm{ft} / \mathrm{min})^{\mathrm{b}}$

Average speed $\left(\bar{v}_{d e}\right)(\mathrm{m} / \mathrm{s})$

Avg. longitudinal deceleration $\left(a_{d e}{ }^{-}\right)\left(\mathrm{m} / \mathrm{s}^{2}\right)$

Distance $\left(r_{d e}\right)(\mathrm{km}, \mathrm{nm})$

Time $\left(t_{d e}\right)(\mathrm{min})^{\mathrm{c}}$

Propulsion efficiency $\left(\eta_{d e}\right)(-)$

Coeff. of the aerodynamic drag: $C_{d / d e}\left(\bar{v}_{d e}\right)(-)^{\mathrm{d}}$

Average air density $\left(\bar{\rho}_{d e}\right)\left(\mathrm{kg} / \mathrm{m}^{3}\right)$
Cruising Speed

$M=\mathbf{2 . 4}$

$0-3-10-65$

9.64

185-250-1376

2806

306

0.468

$289.7 ; 156.4$

$1.2+22.09=23.29$

0.444

0.3

0.4135

65

0.08891

0.006 or 0.001523

729

139

$2 \cdot 42$

3.75

6138

24189

$11426 / 6169$

8.303

0.444

65-10-3-0

9.23

1376-250-175

2619

309

0.435

$382.4 ; 206.5$

$23.67+1.34=25.01$

0.444

0.3

0.4135

${ }^{\text {a }}$ Take-off speed is $185 \mathrm{kt}$; the landing speed is $175 \mathrm{kt}$; the speed at FL10 is $250 \mathrm{kt}$ (FL10 $=10000 \mathrm{ft}$ );

$\mathrm{b}$ the rate of climb: $\mathrm{R} / \mathrm{C}(\mathrm{h})=9000-0.1308 \cdot \mathrm{H}$; the rate of descend: $\mathrm{R} / \mathrm{D}(\mathrm{H})=-8000+0.1154 \cdot \mathrm{H}$ (based on Concorde and TY 144) ( $\mathrm{H}$ is the altitude $\left(10^{3}\right.$ feet));

c the climb/descend time: $\left.t\left(H_{1}, H_{2}\right)=(1 / b) \cdot\left\{\ln \left[a\left(H_{1}\right)-b \cdot H_{2}\right]-\ln \left[a\left(H_{1}\right)-b \cdot H_{1}\right)\right]\right\}\left(\mathrm{H}_{1}, \mathrm{H}_{2}\right.$ is the initial and the end altitude, respectively) ${ }^{(8)}$;

$\mathrm{d}$ attack angle is $=4^{0}$;

${ }^{\mathrm{e}}$ At FL $60-65\left(10^{3} \mathrm{ft}\right)$;

$\mathrm{f}(28)$;

g (24); (25). 
Table 4

Characteristics of aircraft fuels, emissions of GHG, costs/externalities, and GWP (Global Warming Potential) in the given example (66), (67)

\section{Characteristic}

SG - Specific Gravity (kg/L)

$\mathrm{SE}-$ Specific Energy $(\mathrm{MJ} / \mathrm{kg})$

$\mathrm{CO}_{2}(\mathrm{~kg} / \mathrm{kg}$ of fuel)

$\mathrm{H}_{2} \mathrm{O}(\mathrm{kg} / \mathrm{kg}$ of fuel)

$\mathrm{NO}_{\mathrm{x}}(\mathrm{g} / \mathrm{kg} \text { of fuel })^{\mathrm{a}}$

$\mathrm{SO}_{\mathrm{x}}(\mathrm{g} / \mathrm{kg}$ of fuel $)$

$\mathrm{PM}(\mathrm{PM} / \mathrm{kg} \text { of fuel })^{\mathrm{b}}$

$\mathrm{HC}(\mathrm{g} / \mathrm{kg}$ of fuel)

Emission rate $\left(\mathrm{kgCO}_{2 \mathrm{e}} / \mathrm{kg} \text { of fuel }\right)^{\mathrm{c}}$

Cumulative GWP ${ }^{\mathrm{d}}$

Avearge cost of $\mathrm{GHG}$ emissions ( $\$ \mathrm{US} / \mathrm{tonCO}_{2 \mathrm{e}}$ )

- $\mathrm{CO}_{2 \mathrm{e}}{ }^{\mathrm{e}}$

- $\mathrm{NO}_{\mathrm{x}}{ }^{\mathrm{f}}$
Fuel Type/Value

$\begin{array}{lll}\text { Jet } \mathrm{A} & \mathrm{LH}_{2} & \mathrm{GWP}^{a}\end{array}$

$0.804 \quad 0.071$

$43.2 \quad 120$

$\begin{array}{lll}3.162 & 0.0 & 1\end{array}$

$1.230 \quad 3.128 \quad 0.1$

9.0-18.0 $0.05-0.25 \quad 265$

$0.084 \quad 0.00$

$3.0-6.0 \cdot 10^{15} \quad 0.00$

$18.0 \quad 0.00$

$4.42358 \quad 3.12815$

$6.86250 \quad 0.35255$

212

86.4

\footnotetext{
${ }^{\mathrm{a}}$ Direct combustion;

$\mathrm{b}$ engine power is $45-100 \%$; PM - Particulate Matters;

${ }^{\mathrm{c}}$ carbon dioxide equivalent;

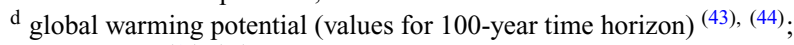

e high impact (48), (73);

${ }^{f}$ high Impact ${ }^{(74)}$.
}

GHG emissions, contribution to global warming and climate change, and costs/externalities: The inputs for estimating GHG emissions of both subsonic and supersonic flights relate to the characteristics of Jet $\mathrm{A}$ and $\mathrm{LH}_{2}$ fuel, their contribution to global warming and climate change and the related costs as externalities is given in Table 4. The related cost of emissions of particular GHG is adjusted for the year 2050.

\subsubsection{Social performance}

The cruising altitude ranging as: $H=36-60 \cdot 10^{3} \mathrm{ft}$ and speed of $M=2.4$ are used as the "what-if" scenario-based inputs for estimating the level of noise produced by supersonic flight(s) as experienced by an observer on the ground.

\subsection{Analysis of the results}

Based on the above-mentioned inputs, the performance indicators are estimated for the average (representative) route of the network where subsonic or supersonic flights are exclusively carried out. These estimates, however, do not compromise in any way the relevance of findings and the related conclusions referring to the entire network. If needed, the corresponding inputs for estimating the performance indicators of each individual route can be estimated in order to obtain the corresponding totals for the entire network. 
Table 5

Indicators of operational performance of an average route of the network in the given example: Transport work, productivity, and required fleet of particular aircraft categories (period: the year 2050)

\section{Inputs/Aircraft category}

$(\mathrm{S} \cdot \lambda)$ - Number of passengers onboard ${ }^{\mathrm{a}}$ $t(R)$ - Average flight time $(\mathrm{h})^{\mathrm{b}}$

$\bar{v}$ - Avearge aircaft speed $(\mathrm{kt} ; \mathrm{km} / \mathrm{h})^{\mathrm{c}}$

$\tau(R)$ - Turnaround time along the route $(\mathrm{h}){ }^{\mathrm{d}}$

$T W$ - Transport work $\left(10^{3} \mathrm{p}-\mathrm{km} /\right.$ route/day $)$

$T P$ - Productivity $\left(10^{3} \mathrm{p}-\mathrm{km} / \mathrm{h} /\right.$ day $)$

$F(\cdot)$ - Number of flights per route/year ${ }^{\mathrm{e}}$

$n(\Delta \tau)$ - Required fleet for the network ${ }^{\mathrm{f}}$

Subsonic
$\boldsymbol{M}<\mathbf{1 . 0}$
210
16.00
$408 ; 756$
$2+2 \cdot 16=34$
2540
158.760
329
35

Supersonic

$M=\mathbf{2 . 4}$

210

8.68

$1164 ; 2155$

$4+2 \cdot 8.68=21.36$

2540

452.55

329

24

\footnotetext{
a Based on the aircraft capacity of $\mathrm{S}=300$ seats/dep and load factor $\lambda=0.7$;

$\mathrm{b}$ includes the standard LTO cycle of $\mathrm{t}_{\mathrm{LTO}}=34.38 \mathrm{~min}$ (Masiol and Harrison, 2014) (h - hour);

${ }^{c}$ based on the average route length of $\mathrm{R}=6532 \mathrm{~nm}(12097 \mathrm{~km})$ (Table 1) and the average flight duration $\mathrm{t}(\mathrm{R})$;

$\mathrm{d}$ based on the aircraft handling time at the origin and the destination airport of $\tau_{0}=1 \mathrm{~h}$;

e based on the aircaft availability of $U=90 \%$ /year and the daily frequency of $\mathrm{f}(\Delta \tau)=1 \mathrm{dep} /$ day;

${ }^{\mathrm{f}}$ based on the flight frequency of $\mathrm{f}(\Delta \tau)=1$ dep/day.
}

\subsubsection{Infrastructural and technical/technological performance}

As mentioned above, the indicators of infrastructural and technical/technological performance are not particularly elaborated. They are assumed as given in the inputs for estimating those of the other performances.

\subsubsection{Operational performance}

The inputs in Tables 1, 2, and AI-1 (Appendix I) are used for estimation of the indicators of operational performance as given in Table 5 .

As can be seen, the flight time by the supersonic aircraft operating at a speed of $M=2.4$ would be almost two times shorter than that of their subsonic counterparts. Consequently, thanks to the shorter route turnaround time, the required fleet of supersonic aircraft would be lower by about $46 \%$. The transports work on an average route and consequently in the network would be equal for both categories of flights. This is mainly due to the equal flight frequencies, seat capacity, load factor, and the average route length. However, thanks to the higher cruising speed, the technical productivity of supersonic flights would be about 2.9 times greater than that of their subsonic counterparts.

\subsubsection{Economic performance}

Flight cost

The total operating cost of a subsonic flight is derived from Eq. $1 \mathrm{~b}$ and the adjustments reflecting the expected conditions in the year 2050, as follows: $C(R, S)_{2050}=\left[\left(a_{0}+a_{1} \cdot R+\right.\right.$ $\left.\left.a_{2} \cdot S\right)_{2019} \cdot t(R)\right]\left[\left(1-p_{f c}\right)+p_{f c} \cdot\left(1+i_{r}\right)^{30} \cdot\left(1-r_{f c}\right)\right]=[(177.479+0.301 \cdot 6532+$ $21.965 \cdot 300) \cdot 16] \cdot\left[(1-0.4)+0.4 \cdot(1+0.012)^{30} \cdot(1-0.4)\right]=131761 \$$ US/flight. The average cost per flight is equal to: $\bar{c}_{-/ 2050}=C(R, S)_{2050} /(R \cdot \lambda \cdot S)=131761 /(6532 \cdot 1.852 \cdot 0.7$. 
Table 6

Indicators of economic performance of an average route of the network in the given example: Cost of passenger time and its potential savings at particular categories of flights (period: the year 2050)

Inputs

$t(R)$-Average flight time (h)

$\alpha$ - Value of passenger time (\$US/p-h) ${ }^{a}$

Cost of time per flight $\left(10^{3} \$ \text { US/flight }\right)^{b}$

Total costs of time in the network $\left(10^{3} \$ \mathrm{US} / \text { day }\right)^{\mathrm{c}}$

Total savings in the cost of time $\left(10^{3} \$ \mathrm{US} / \text { day }\right)^{\mathrm{c}}$

$\bar{c}_{s v / 2050}$ - Average savings in the cost of time (\$US/p-km) \begin{tabular}{cc}
\multicolumn{2}{c}{ Flight Category } \\
Subsonic & Supersonic \\
$M<1.0$ & $M=2.4$
\end{tabular}

16.00

74

248.640

6216

0

0
8.681

74

134.903

3372.56

2843.50

0.0448

${ }^{\text {a }}$ Based on 50\% medium-and 50\% high-income passngers on board and their $50 \%$ business and $50 \%$ leisure trips (50), (51);

$\mathrm{b}$ based on the route length of $R=12097 \mathrm{~km}(6532 \mathrm{~nm})$, the aircraft seat capacity of $S=300$ seats/dep, and the load factor of $\lambda=0.7$;

${ }^{\mathrm{c}}$ based on 25 flights/day in the network.

$300)=0.052 \$ U S / p-k m\left(p_{f c}=0.4\right.$ is the share of fuel cost in the total aircraft operating cost in Eq. $\left.1 b^{(49),(53)}\right) ; r_{f_{c}}=0.4$ is the cumulative rate of improvement in aircraft fuel efficiency in the year 2050 vs $2019 / 2020^{(54)} ; i_{r}=1.2 \%$ is the annual rate of increasing prices of crude oil, which proportionally influences an increase in the price of Jet-A fuel during the period 2018/19-2050 $0^{(55)}$.

The total cost of a flight carried out by supersonic aircraft is estimated as follows:

The fixed cost of the fleet of 24 aircraft $(M=2.4)$ in Table 5, carrying out 329 flights/year on each of 25 routes of the network in Table 1, is estimated as follows: $C_{F / 2050}$ $=\left[24 \cdot\left(450 \cdot 10^{6}\right) \cdot 0.045\right] /(329 \cdot 25)=59088(\text { SUS/flight })^{(24)}$, the crew cost: $c_{c w / 2050}=2000$ $\$ U S / h \cdot 8.681 \mathrm{~h}=17362$ \$US/flight ${ }^{(56)}$, and the fuel cost: $c_{f c / 2050}=93516 \mathrm{kgLH}_{2} /$ flight - $1 \$ U S / k g L_{2}=93516$ \$US/flight (see also below) $)^{(48)}$. If the above-mentioned (three) cost components are assumed to account for about $70 \%$ of the total flight operating cost, the corresponding total cost will be: $C_{T / 2050}=\left(C_{F / 2050}+c_{c w / 2050}+c_{f c / 2050}\right) / 0.7=$ $(59088+17362+93516) / 0.7=242809$ \$US/flight. The average cost of single flight carried out on the route: $R=6532 \mathrm{~nm}(12097 \mathrm{~km})$ (by the aircraft of: $S=300$ seats and load factor: $\Lambda=0.70$ is equal to: $\overline{\mathrm{c}}_{-/ 2050}=C_{T / 2050} /(R \cdot \lambda \cdot S)=242809 /(6532 \cdot 1.852 \cdot 0.7 \cdot 300)=0.096$ $\$ \mathrm{US} / \mathrm{p}-\mathrm{km}$. If the fuel cost is $0.85 \$ \mathrm{US} / \mathrm{kgLH}_{2}{ }^{(48)}$, the corresponding average cost of the supersonic flight would be: $\overline{\mathrm{c}}_{-/ 2050}=155939 /(6532 \cdot 1.852 \cdot 0.7 \cdot 300)=0.061 \mathrm{\$ US} / \mathrm{p}-\mathrm{km}$. Figure 5 shows these average cost per flight.

As can be seen, at the frequency of $1 \mathrm{flight} /$ day, the average operating cost of the supersonic flight, depending on the fuel cost, would be between $18 \%\left(0.85 \$ \mathrm{US} / \mathrm{kgLH}_{2}\right)$ and $85 \%$ ( $1 \mathrm{SUS} / \mathrm{kgLH}_{2}$ ) higher than that of the subsonic flight. This example indicates that the supersonic flights would generally be economically inferior to their subsonic counterparts under the given conditions.

Cost of passenger time: The cost of passenger time and the potential savings in this cost by using the supersonic instead of the subsonic flight(s) are given in Table 6. 


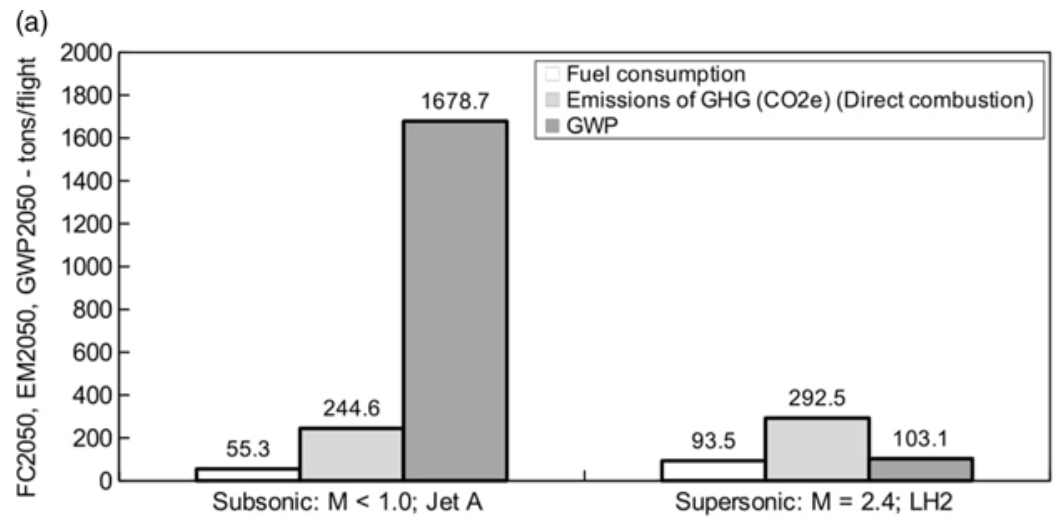

(b)

Flight category

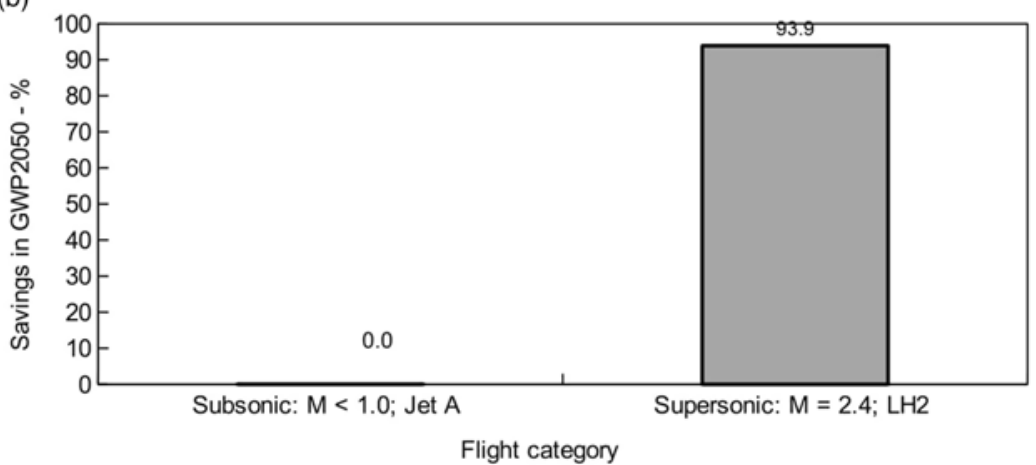

Figure 6. Indicators of environmental performance of particular categories of flights carried out on an average route of the network in the given example (period: the year 2050) a) fuel consumption, emissions of GHG, and GWP; b) savings in the contribution to GWP.

As can be seen the cost of passenger time would be about $50 \%$ lower for the supersonic flights. The corresponding savings in this cost would be about $4.5 \mathrm{~d} / \mathrm{p}-\mathrm{km}$.

\subsubsection{Environmental performance}

The fuel consumption of subsonic flights in the given example is derived from Eq. 1c, while respecting the prospective improvements in the aircraft fuel efficiency of $r_{f c} \approx 0.4$ by the year $2050^{(57)}$. Consequently, the fuel consumption of a flight carried out by an aircraft with a seat capacity of $S=300$ seats along the route $R=12097 \mathrm{~km}(6532 \mathrm{~nm})$ would be $F C_{2050}(R)=55.3$ tons/flight (Jet A fuel). Under the same conditions, by applying the models in Appendix III to the inputs from Table 4, the average fuel consumption of the supersonic flight is estimated as: $F C_{2050}(R)=1.02\left(F C_{c l}+F C_{c r}+F C_{d e}\right)=1.02 \cdot(9245+76089+6339)=1.02$. $91687 \approx 93516 \mathrm{~kg} /$ flight $\left(\mathrm{LH}_{2}\right)$. In this case the factor 1.02 is applied to include the fuel consumed during the LTO cycle. The inputs in Table 4 and the above-estimated fuel consumption are used for estimating GHG emissions and their absolute and relative contribution to global warming and climate change as shown in Fig. 6 (a, b).

Figure 6 a shows that the average fuel consumption by the supersonic flight would be about $70 \%$ higher than that of the subsonic flight. The corresponding GHG emissions would be also higher by about $19 \%$. At the same time, the GWP of the subsonic flight would be about 16 

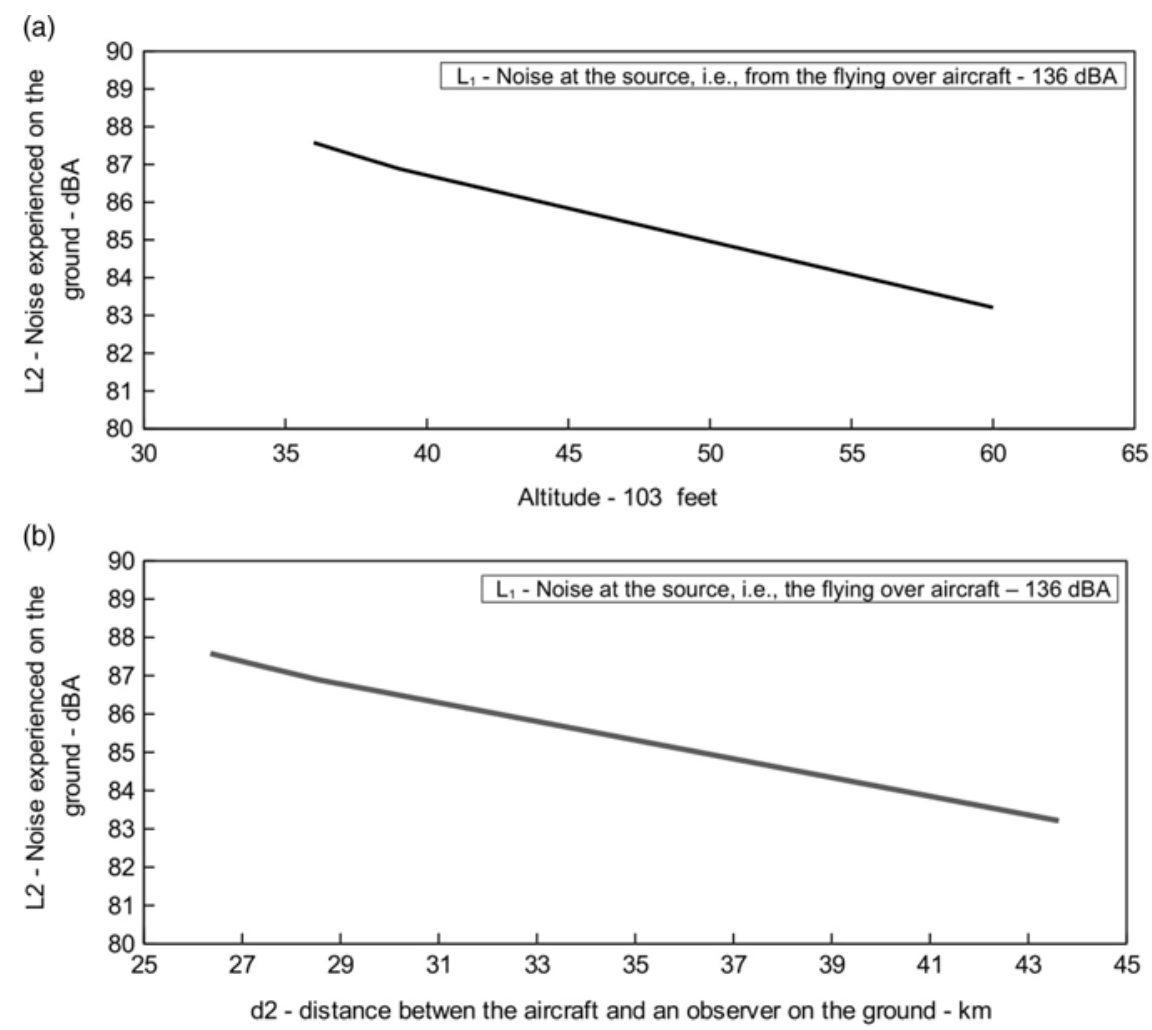

Figure 7. Indicators of social performance: Relationship between the noise levels generated by supersonic flight $(M=2.4)$ passing above an observer on the ground in the given example (period: the year 2050). a) Noise vs cruising altitude; b) noise vs distance from an observer on the ground.

times higher than that of its supersonic counterpart $\left(\mathrm{CO}_{2}\right.$ and $\mathrm{H}_{2} \mathrm{O}$ dominate in Jet-A and $\mathrm{H}_{2} \mathrm{O}$ in $\mathrm{LH}_{2}$ fuel). Figure $6 \mathrm{~b}$ shows that despite the higher fuel consumption and related $\mathrm{GHG}$ emissions, the supersonic flight(s) could substantially contribute to savings (about $94 \%$ ) in the overall GWP and consequently global warming and climate change, both compared to their subsonic counterparts.

\subsubsection{Social performance}

The noise generated by the supersonic flight(s) operating on an average route of the network is shown in Fig. 7 (a, b).

Figure 7a shows that the noise produced by a supersonic flight passing above an observer on the ground would decrease with the increase of the cruising altitude. Figure $7 \mathrm{~b}$ shows that increasing the distance between the overflying aircraft and an observer on the ground, due to an increase of the cruising altitude, would contribute to the decreasing of the experienced noise of an observer on the ground. The levels of noise generally between 83 and $88 \mathrm{dBA}$ do not reflect barely audible explosion (physical phenomenon) and have been the subject of undesirable psychological reactions. As such, these noise levels appear to be about 6-13\% above U.S. NASA's suggested tolerable levels from the sonic boom, set at about $78 \mathrm{~dB}^{(39)}$. Additionally, the size of the area covered by the noise from the Mach cone needs to be taken 


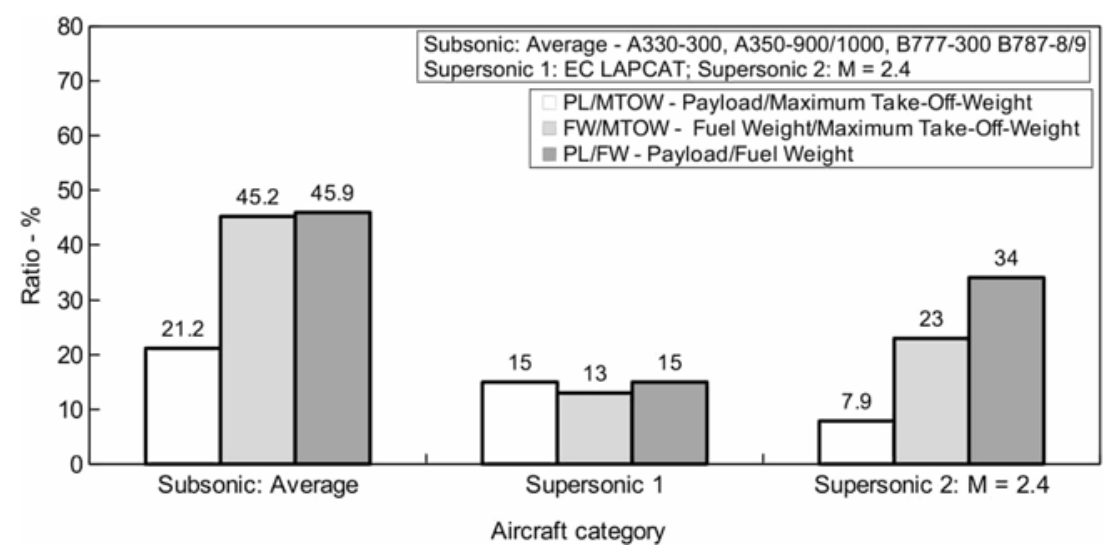

Figure 8. Some (design-related) derived indicators of technical/technological performance of subsonic and ssssupersonic aircraft in the given example (Period: the year 2050) (24), (28), (32), (62), (63).

into account. Both these are and will certainly be used as inputs in considering the possible noise constraints on operations of the supersonic aircraft ${ }^{(12),(39),(58)}$.

\subsubsection{Some derived indicators of performance}

Aircraft design: The maximum take-off weight, payload including only the passengers and their baggage, and the fuel consumption allow for the estimation of some the design-related derived indicators of the technical/technological performance of both subsonic and supersonic aircraft. These are expressed by the ratios such as: PL/MTOW (Payload/Maximum Take-OffWeight), FW/MTOW (Fuel Weight/Maximum Take-Off-Weight), and PL/FW (Payload/Fuel Weight) as shown in Fig. 8.

As can be seen, the particular ratios would be quite different for subsonic and considered supersonic aircraft. For example, the ratio PL/MTOW is about $21 \%$ for subsonic and $8 \%$ at supersonic aircraft. (Full payload for supersonic aircraft: $31500 \mathrm{~kg} ; 1$ passenger + baggage $\left.=105 \mathrm{~kg}^{(59)}\right)$. The ratio FW/MTOW is about $45 \%$ for subsonic and $23 \%$ for supersonic aircraft, the latter also influenced by the fuel type. Finally, the rate PL/FW is about $46 \%$ for subsonic and 34\% for supersonic aircraft, the latter again influenced by the fuel type.

Economics and environment: The derived indicators of economic and environmental performance of an average route and the entire network are considered through the relationship between the flight operating cost, the cost of GHG emissions, i.e. externalities, and the savings in the cost of passenger time, as shown in Fig. 9 (a, b).

Figure 9 shows the difference between the average total cost and its components of the subsonic and supersonic flight on an average route of the network. As can be seen, the average total cost would be lower for the supersonic than for the subsonic flight, by about $20 \%$. This would be achieved thanks to its lower externalities and higher potential savings in passenger time despite the higher operational costs. Consequently, this example indicates that internalising all costs of the particular actors/stakeholders involved in both the demand and the supply side of the given air route network could eventually make supersonic flights economically feasible under the given conditions.

The overall social-economic feasibility: The relationship between the average total monetary contribution to the GDP and the average total cost of both subsonic and supersonic flight(s) carried out on an average route of the network is shown in Fig. 10. 


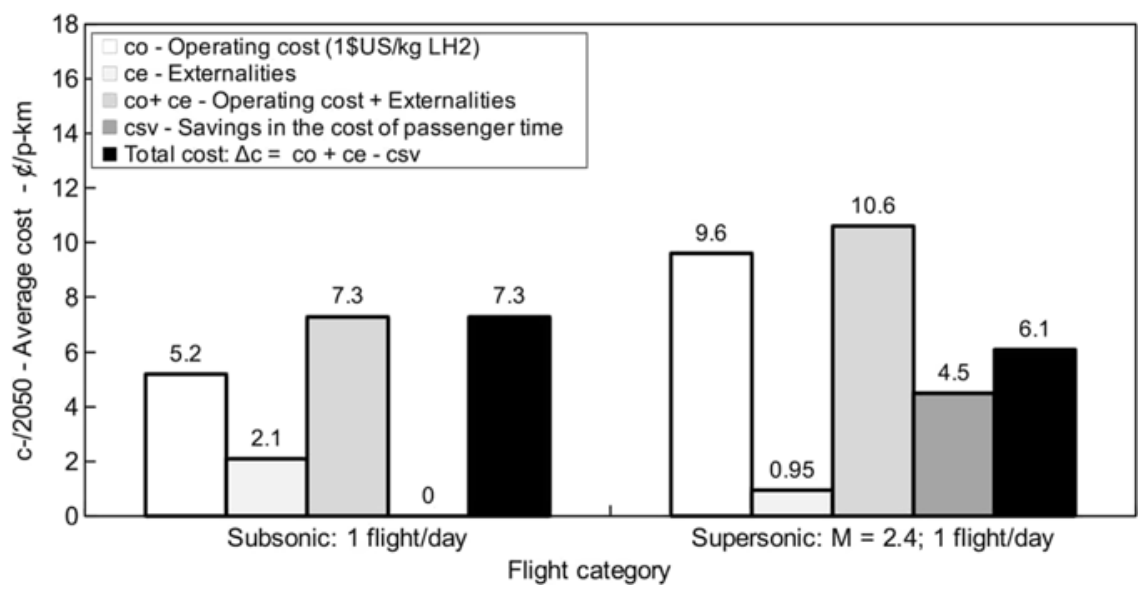

Figure 9. Indicators of the economic performance: The average costs of particular categories of flights carried out on an average route of the network in the given example (period: the year 2050).

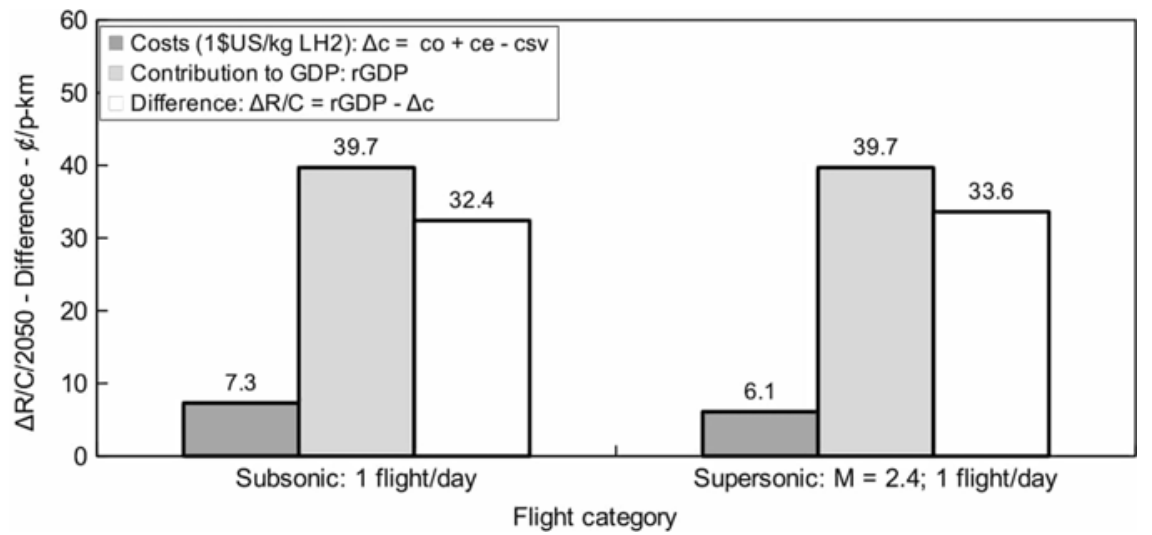

Figure 10. Indicators of social-economic performance: The average contribution to GDP and the average total costs of particular categories of flights carried out on an average route of the network in the given example (period: the year 2050).

As can be seen, in the cases of both subsonic and supersonic flights the average contribution to GDP would be overall higher than the average total cost thus making their difference generally net positive. This difference would be about $5 \%$ greater for supersonic flights compared to subsonic flights. The above figures indicate that supersonic flights could eventually be overall social-economically feasible but only under the considered circumstances.

The above-mentioned results enable synthesising some qualitative pros and cons of supersonic flights, relevant for the particular actors/stakeholders involved, which are summarised as follows:

These pros and cons indicate that the full implementation of the future supersonic commercial flights is and will remain a challenge for all above-mentioned main actors/stakeholders involved. 
ACTOR/STAKEHOLDER

Aircraft manufacturers - Potential profitability of manufacturing the aircraft
Airlines

Airports

Users/air passengers

Local communities

Policy makers/society
- Shorter flight time and higher technical productivity enabling $\mathrm{mor}$ flights if justified by air passenger demand

- Smaller fleet size

- Lower costs of GHG emissions (if internalised)

- Do not require substantial re-design (modification) of the airside and landside area

- Substantial savings in time cost

- Availability of supersonic air transport services at the nearby airports

- Contribution to reducing global warming and climate change

- Overall social-economic/ feasibility

\section{CONS}

- Complexity in delivering the economically, environmentally, and socially feasible aircraft design

- Inherent risk of failure to deliver the expected/required design

- Inherent uncertainty in deployment

- Higher operating cost requiring higher airfares, which could compromise expected air passenger demand

- Provision of the supply of the new $\left(\mathrm{LH}_{2}\right)$ fuel

- Noise as the subject for further regulation

- Higher potentially deterring airfares based on higher operational cost and internalised externalities (GHG emissions)

- Additional costs of insulating or relocating houses due to the increased noise if these would not be regulated similarly to current subsonic aircraft/flights - Higher fuel consumption and related GHG emissions, particularly the impact from the $\mathrm{LH}_{2}$ generated $\mathrm{NO}_{\mathrm{x}}$ on $\mathrm{O}_{3}$ (Ozone) layer

- Noise around airports and from the sonic boom, as the subject of further regulation - Uncertainty and inherent complexity of implementation - Complexity in internalizing and then considering all direct and indirect impacts/costs and effects/revenues in assessing the overall social/economic feasibility/benefits 


\section{CONCLUSIONS}

This paper has modelled the performance of a given long-haul air transport network operated by existing subsonic and prospectively forthcoming supersonic commercial aircraft. Infrastructural, technical/technological, operational, economic, environmental, and social performance has been considered. Analytical models of the performance indicators have been developed.

The indicator models have been applied in estimating the performance of an existing air route network, consisting of 25 long-haul routes operated exclusively by commercial subsonic aircraft (currently) and supersonic (prospectively by the year 2050) aircraft.

The input for the estimation of the performance indicators of the network and its average route was empirical data for subsonic aircraft/flights, available data from the corresponding design concepts of supersonic aircraft/flights, and the elements of the specified "what-if" operational scenarios The subsonic aircraft are assumed to be powered by Jet-A fuel and the supersonic aircraft by $\mathrm{LH}_{2}$ (Liquid Hydrogen) fuel.

The results have indicated that:

- The supersonic and subsonic flights carried out on the same routes with the same frequency, seat capacity, and load factor would perform the same transport work. The supersonic flights would have about 2.9 time higher technical productivity thanks to the much higher cruising speed. The required fleet size of supersonic aircraft would be about $46 \%$ smaller than that of the subsonic ones, thanks to the higher cruising speed and the consequently shorter turnaround time on the route(s).

- The operating cost of supersonic flights, depending on the fuel cost, would be about 18 $85 \%$ higher than that of the subsonic flights. This has confirmed concerns about their future economic feasibility from the airline perspective. However, these flights would provide the substantial savings in passenger time costs, of up to $46 \%$.

- The fuel consumption and related GHG emissions of the supersonic flights would be about $70 \%$ and $19 \%$, respectively, higher than those of the subsonic flights. This would primarily be due to much higher fuel consumption of $\mathrm{LH}_{2}$ fuel, mainly caused by much higher operating speeds despite its much higher energy content, compared to Jet-A fuel. However, despite being higher, the costs GHG emissions have shown to be much lower thanks to the prospective charges/externalities. Combined with their GWP (global warming potential), GHG emissions by supersonic flights would contribute to savings in global warming and climate change of up to about $94 \%$. The supersonic aircraft would generally not substantially compromise land use as an environmental externality. The possible impact of the logistics of supplying $\mathrm{LH}_{2}$ fuel in this context remains to be further considered.

- The noise levels produced by supersonic aircraft at airports and during cruising at higher altitudes would be about $6-13 \%$ above certain prescribed tolerable level(s). Therefore, this (noise) externality will continue to be an important subject in the further dealings with commercialization of supersonic aircraft/flights.

- The selected derived design-related indicators of the technical/technological performance of supersonic aircraft, such as the payload/weight, fuel/weight, and payload/fuel ratio would be about $13 \%, 22 \%$, and $12 \%$, respectively, lower than that of subsonic aircraft. This indicates inherent specificities and challenges in their future design.

- If all the above-mentioned costs were fully internalised as externalities, supersonic flights could be about $20 \%$ more beneficial than their subsonic counterparts. This would be the 
case only if the noise burden and the risk of air traffic incidents/accidents (i.e. safety) externalities are not taking fully into account.

Furthermore, estimation of the particular performance indicators for the network operated by supersonic aircraft was carried out by using secondary sources and available data predominantly from the U.S. airline industry. Some of them have been based on analogy with those related to subsonic aircraft/flights carried out in the network according to equivalent scenarios. Therefore, in addition to this initial step, future research could be directed towards:

- Refining the existing and developing additional performance indicators, including their more refined estimation by using more global and reliable data;

- Developing more realistic future scenarios of operating air route network(s) implying estimation of passenger demand, respecting the eventual airline/flight category competition; and

- Obtaining more refined estimates of the contribution of particular flight categories to the GDP and particularly to the environmental and social costs/externalities.

These all would contribute to the more detailed and reliable evaluation of the overall socialeconomic feasibility of the possible further development and implementation of commercial supersonic aircraft/flights by the year 2050 .

\section{REFERENCES}

1. Vuchic, R.V. and Casello, M.J. An evaluation of Maglev technology and its comparison with High Speed Rail, Transportation Quarterly, 2002, 56, (2), pp 33-49.

2. Howard, E. W., (Ed.) Impact of advanced air transport technology: Part 1: Advanced high speed aircraft, NTIS order \#PB83-110585, U.S. Government Printing Office, Washington, D.C. 20402 Stock No. 052-003 -00745-2, USA, 1980.

3. https://www.nationalgeographic.com/environment/urban-expeditions/transportation/passengeraircraft-milestones/.

4. https://www.grc.nasa.gov/WWW/K-12/airplane/mach.html/.

5. ICAO. Environmental protection: Volume I - Aircraft noise, Annex 16, $5^{\text {th }}$ Edition, International Civil Aviation Organization, Montreal, Canada, 2008.

6. Boeing. Statistical summary of commercial jet airplane accidents worldwide operations: 19592016, Boeing Commercial Airplanes, Seattle, Washington, USA, 2017.

7. https://aviation-safety.net/statistics/.

8. NASA. NASA Armstrong fact sheet: Tu-144LL Supersonic Flying Laboratory, National Aeronautics and Space Administration, Washington DC, US, 2017.

9. http://www.concordesst.com/home.html/.

10. http://www.tu144sst.com/index.html/.

11. https://www.nasa.gov/centers/armstrong/news/FactSheets/FS-062-DFRC.html/.

12. FAA. Fact sheet - supersonic flight, Federal Aviation Administration, Washington DC, US, https://www.faa.gov/news/fact_sheets/news_story.cfm?newsId=22754, 2018.

13. JANić, M. Advanced Transport Systems: Analysis, Modelling, and Evaluation of Performances, Springer, UK, 2014.

14. MASEFIELD, G.P. Can Concorde make a profit? Flight International, 10 August, 1972, pp 214-216.

15. http://www.baaa-acro.com/events/.

16. NASA. NASA AERONAUTICS - Strategic implementation plan 2017 update, National Aeronautics and Space Administration, Washington, DC, US, 2017.

17. Ingenito, A., Guldi, S. and Bruno, C. Preliminary sizing of an hypersonic air breathing airliner, Transactions of the Japan Society for Aeronautical and Space Sciences, Aerospace Technology Japan, 2010, 8, (27), pp 19-28. 
18. Kharina, A., MacDonald, T. and Rutherford, D. Environmental performance of emerging supersonic transport aircraft, Working Paper 2008-12, ICCT-The International Council on Clean Transportation, www.theicct.org/, 2018.

19. Norris, G. and WARWICK, G. NASA Focuses supersonic effort on low-boom propulsion, Aviation Week \& Space Technology, June, 2012.

20. Sippel, M. and Klevanski, J. Preliminary definition of supersonic and hypersonic airliner configurations, AIAA (American Institute of Aeronautics and Astronautics), Paper 2006-7984, 14th AIAA/AHI Space Planes and Hypersonic Systems and Technologies Conference, 06-09 November, Canberra, Australia, 2006.

21. UNDERWOOD, C.M. Concept of operations for integrating commercial supersonic transport aircraft into the National Airspace System, Technical Report, December 2017, National Aeronautics and Space Administration, Langley Research Centre Hampton, Virginia, USA, 2017.

22. Boom Supersonic. Boom has risen 33M in new funding to finish development and flight test of XB-1, https://blog.boomsupersonic.com/boom-has-raised-33m-innew-funding-to-finish-development-and-flight-test-of-xb-1-c82e1f556c43/, 2017.

23. Spike Aerospace. Spike Aerospace expands quiet supersonic aircraft development Efforts, www.spikeaerospace.com/spike-aerospace-expands-quiet-supersonicaircraft-development-effort/, 2017.

24. EC. LAPCAT (Long/Term Advanced Propulsion Concepts and Technologies), European Commissions Sixth Framework Program, Final Public Report, Thematic Priority 1.4 Aeronautics and Space, Brussels, Belgium, 2008.

25. Steelant, J. LAPCAT: High-Speed Propulsion Technology, in Advances in Propulsion Technology for High Speed Aircraft-Volume II, Paniagua, G, Steelant, J. Eds, RTO-AVT-VKI Lecture Series 2007, Von Karman Institute for Fluid Dynamics, Rhode Saint Genese, Belgium, 2008.

26. Grant, G.R. Flight: The Complete History of Aviation, (Updated, Revised Edition), DK Publishing, New York, USA, 2017.

27. Saltzman, J.E. and Ayers, G.T. Selected examples of NACA/NASA supersonic flight Research, NASA Special Publication 513, National Aeronautics and Space Administration, Dryden Flight Research Center Edwards, California, USA, 1995.

28. NAS. Commercial supersonic technology: The way ahead, National Academy of Sciences, National Academic Press, Washington, DC, US, 2001.

29. WiLliams, J.L. Estimated aerodynamics of all body hypersonic aircraft configurations, NASA Technical Memorandum, NASA TM X-2091, National Aeronautics and Space Administration, Washington, DC, US, 1971.

30. Chambers, R.J. Innovation in flight: Research of the NASA Langley Research Centre on revolutionary advanced concepts for aeronautics, National Aeronautics and Space Administration, NASA SP-2005-4539, Washington, DC, US, 2005.

31. Westenberger, A. Liquid hydrogen fueled aircraft-system analysis (CRYOPLANE), Final Technical Report, Revision 1. Airbus Deutschland GmbH, Hamburg, Germany, 2007.

32. Coen, P. Fundamental aeronautics program: Supersonic projects, 2011 Technical Conference, National Aeronautic and Aerospace Administration, Cleveland, Ohio, USA, 2011, p. 34.

33. McClinton, C.R. High speed/hypersonic aircraft propulsion technology development, In Advances on Propulsion Technology for High-Speed Aircraft. Educational Notes RTO-EN-AVT150, Paper 1. Neuilly-sur-Seine, France: RTO. Available from: http://www.rto.nato.int/, 2008, pp $1-1-1-32)$

34. https://www.independent.co.uk/news/science/hypersonic-jet-boeing-two-hour-london-new-yorkflight-transatlantic-speed-a8422636.html/.

35. Fenrm, B. Aerion's supersonic engine presented, Leeham News and Comment, https://leehamnews.com/2018/02/26/aerions-supersonic-engine-presented/, 2018.

36. Reichmuth, J. Berster, P. Past and future developments of the global air traffic, in Biokerosene Status and Prospects, Kaltschmitt, M., Neuling, U. (eds.), Springer-Verlag GmbH, Germany, doi: 10.1007/978-3-662-53065-8_2, 2018, pp 13-31.

37. Liebhardt, B., Luetjens, K. and Gollnick, V. Estimation of the market potential for supersonic airliners via analysis of the global premium ticket market, 11th AIAA Aviation Technology, Integration, and Operations (ATIO) Conference, ISBN: 978-1-60086-941-9, https://doi.org/10.2514/6.2011-6806, Virginia Beach, VA, USA, 20-22 September, 2011. 
38. Sun, Y. and Smith, H. Review and prospect of supersonic business jet design, Progress in Aerospace Sciences, 90, 2017, pp 12-38.

39. CRS. Supersonic passenger flights, Congressional Research Service, CRS Report R45404 Prepared for Members and Committees of Congress, Washington, DC, US, https://crsreports.congress.gov/, 2018.

40. Portmann, W.R., Daniel, S.J. and Ravishankara, R.A. Stratospheric ozone depletion due to Nitrous Oxide: Influences of other gases, Philosophical Transaction of Royal Society, 2012, 367, 1256-1264, DOI: 10.1098/rstb.2011.0.377.

41. Upham, P., Maughan, J., Raper, D. and Callum, T. (eds.). Towards Sustainable Aviation, Earthscan Publications Ltd, London/Sterling, UK, 2003.

42. IATA. Airline disclosure guide: Aircraft acquisition cost and depreciation, International Air Transport Association, Montreal, Canada, 2016.

43. Derwent, R., Simmonds, P., O’Doherty, S., Manning, A., Collins, W. and Stevenson, D. Global environmental impacts of the hydrogen economy, International Journal of Nuclear Hydrogen Production and Applications, 2006, 1, (1), 57-67

44. IPCC. Climate change 2014, Synthesis Report - Contribution of Working Groups I, II and III to the Fifth Assessment Report of the Intergovernmental Panel on Climate Change [Core Writing Team, R. K. Pachauri and L. A. Meyer (eds.)], IPCC, Geneva, Switzerland, 2014, p. 151.

45. http://hyperphysics.phy-astr.gsu.edu/hbase/Acoustic/isprob2.html/.

46. Airbus. Airbus aircraft 2018 average list prices (USD millions), Information, Airbus Media Relations, Blagnac, France, 2018.

47. https://www.airbus.com/content/dam/corporate-topics/publications/backgrounders/Airbus-Commercial-Aircraft-list-prices-2018.pdf/.

48. NAE. The hydrogen economy: opportunities, costs, barriers, and $R \& D$ needs, National Academy of Engineering, The National Academies Press, Washington, DC, US, https://doi.org/10.17226/10922, 2004.

49. https://www.planestats.com/bhsw_2017mar/.

50. NASEM. Passenger value of time, Benefit-cost analysis and airport capital investment decisions, Volume 2, Final Report, National Academies of Sciences, Engineering, and Medicine, The National Academies Press, Washington, DC, US, https://doi.org/10.17226/22161, 2015.

51. USDT. Revised 26 departmental guidances on valuation of travel time in economic analysis, U.S. Department of Transportation, Office of the Secretary of Transportation, Washington, DC, US, 2014.

52. ATAG. Aviation benefits beyond borders, Air Transport Action Group, Geneva, Switzerland, 2018.

53. https://www.transtats.bts.gov/Tables.asp/.

54. Gareth, H. Future aircraft fuel efficiencies, Final Report, Department for Transport under the Future Aircraft Fuel Efficiencies Study, proposal reference ED47903, under the Lot 2 Framework Contract, PPRO4/45/004, QINETIQ/10/00473, Farnborough, UK, 2010.

55. EIA. Annual energy outlook 2019 with projections to 2050, U.S. Energy Information Administration, Office of Energy Analysis, U.S. Department of Energy, Washington, DC, US, 2019.

56. www.PlaneStats.com/.

57. Horton, G. Future aircraft fuel efficiencies, Final Report, QINETIQ/10/00473, Farnborough, UK, 2010.

58. USAF. Sonic boom, United States Air Force, 6WWP 105-1-1, No. 105-1-1, Washington, DC, US, 1966.

59. BAXTER, S.G. and BARDELL, S.N. Can the renewed interest in ultra-long-range passenger flights be satisfied by the current generation of civil Aircraft, Aviation, 2017, 2, (21), pp 42-54.

60. ICAO. Airport air quality manual, Doc 9889, First Edition, Corrigendum No. 1, International Civil Aviation Organization, Montreal, Canada, 2011.

61. Jenkinson R.L., Simpkin, P. and Rhodes, D. Civil Jet Aircraft Design, Arnold, (The Hodder Headline Group), London, UK, 1999.

62. https://www.boeing.com/commercial/.

63. https://www.airbus.com/aircraft/support-services/airport-operations-and-technical-data/aircraftcharacteristics.html/.

64. JANIĆ, M. The potential of liquid hydrogen for the future 'carbon neutral' air transport system, Transportation Research D, 2008, 7, (13), pp 428-435. 
65. https://www.travelcodex.com/the-worlds-longest-flights-march-2018/.

66. NASA. Alternative aviation fuel experiment (AAFEX), NASA/TM-2011-217059, National Aeronautics and Space Administration, Washington, DC, US, 2011.

67. JANIĆ, M. An Assessment of the potential of alternative fuels for "greening" commercial air transportation, Journal of Air Transport Management, 2018, 69, pp 235-247. http://dx.doi.org/10.1016/j.jairtraman.2017.09.002/.

68. Banavar, S.B., NG, K.H., Linke, F. and Chen, Y.N. Benefits analysis of wind-optimal operations for trans-Atlantic flights, 14th AIAA Aviation Technology, Integration, and Operations Conference, AIAA Aviation, Atlanta, USA, 16-20 June 2014.

69. EEC. Base of aircraft data (BADA), Aircraft Performance Modelling Report, EEC Technical/Scientific Report No. 2009-009, Eurocontrol Experimental Centre, European Organization for the Safety of Air Navigation, Brétigny-sur-Orge CEDEX, France, 2009.

70. Graver, B. and Rutherford, D. Transpacific airline fuel efficiency ranking 2016, ICCT (International Council on Clean Transportation), Washington, DC, US, 2018.

71. PARK, Y. and O'KeLLY, E.M. Fuel burn rates of commercial passenger aircraft: Variations by seat configuration and stage distance, Journal of Transport Geography, 2014, 41, pp 137-147.

72. https://www.businessinsider.com/longest-flights-in-the-world-ranked-oag-2018-1/.

73. Kuchemann, D. Aerodynamic Design of Aircraft, Pergamon Press, London, UK, 1978.

74. IWG. Technical support document: Technical update of the social cost of carbon for regulatory impact analysis under executive order 12866 (September 2016 Revision), Interagency Working Group on the Social Cost of Greenhouse Gases, Washington, DC, US, 2016.

75. Paul, I., Howard, P. and Schwartz, A.J. The Social cost of greenhouse gases and state policy: A frequently asked questions guide, Institute for Policy Integrity, New York University School of Law, New York, USA, 2017.

76. https://go.nasa.gov/2tdiNif/.

77. SA. Spike Aerospace to fly the first SX-1 demonstrator, https://www.spikeaerospace.com/spikeaerospace-to-fly-the-first-sx-1-demonstrator/, 2017.

\title{
6 APPENDICES
}

\section{Appendix I. Inputs for estimating the relationship between the techni- cal productivity of supersonic aircraft and the influencing factors (Eq. 2)}

\author{
Table Al-1 \\ Speed, seat capacity, and technical productivity of the past and future \\ concepts of supersonic aircraft
}

Aircraft type
Concorde (Past)
TY 144 (Past)
Small $^{\text {a }}$
Medium $^{\text {b }}$
Large $^{c}$
LAPCAT Hydrogen Mach
5 Cruiser A2
Boom Aircraft $^{\text {e }}$

Capacity $S$ (Seats)

128

140

15

200

300

300

55
Maximum Cruising
Speed $v(k t)$

1170

1233

1032

1262

1376

2867

1262
Technical Productivity TP $\left(10^{3} s-k t\right)$

149.760

172.620

15.480

252.400

412.800

860.100

69.410 
Table Al-1

\section{Continue}

$\begin{array}{lccc}\text { Aircraft type } & \begin{array}{c}\text { Capacity } \\ \boldsymbol{S}(\boldsymbol{S e a t s})\end{array} & \begin{array}{c}\text { Maximum Cruising } \\ \text { Speed } \boldsymbol{v}(\boldsymbol{k t})\end{array} & \begin{array}{c}\text { Technical Productivity } \\ \boldsymbol{T P}\left(\mathbf{1 0}^{\mathbf{3}} \boldsymbol{s}-\boldsymbol{k t}\right)\end{array} \\ \text { NASA N + 2 } & 70 & 1032 & 72.241 \\ \text { Aerion AS2 } & 12 & 860 & 10.320 \\ \text { Spike S-512 } \mathrm{g} & 18 & 917 & 16.512\end{array}$

a Supersonic Business Jet;

${ }^{\mathrm{b}}$ Overland Supersonic Commercial Transport ${ }^{(16)}$;

${ }^{\mathrm{c}}$ High-Speed Civil Transport ${ }^{(28)}$;

$\mathrm{d}(24) ; e^{(22)} ; f(75) ; g(23),(76)(s-s e a t ; k t-k n o t)$

\section{Appendix II. Models for estimating the time of supersonic flight on a given route}

The total flight time:

$$
t_{k}\left(R_{k}\right)=t_{k / c l / .}+t_{k / c r / .}+t_{k / d e / .}+t_{k / L T O}
$$

Climbing time and distance:

- Time:

$$
\left.t_{k / c l / .}\left(H_{k / c r}-H_{k / c l}\right)=\frac{\left(H_{k / c r}-H_{k / c l}\right)}{R / C(H)}=(1 / b)\left\{\begin{array}{c}
\ln \left[a\left(H_{k / c l}\right)-b \cdot\left(H_{k / c r}\right]\right. \\
\ln \left[a\left(H_{k / c l}\right)-b \cdot H_{k / c l}\right)
\end{array}\right]\right\}
$$

The aircraft rate of climb $R / C(H)$ is expressed as: $\mathrm{R} / \mathrm{C}(\mathrm{H})=\mathrm{a}-\mathrm{b} \cdot \mathrm{H}$, i.e. as approximately linearly decreasing with altitude $\left((H) \text { is the altitude }-10^{3} \text { feet }\right)^{(8)}$.

- Distance:

$$
r_{k / c l / .}=\left(H_{k / c r}-H_{k / c l}\right) / \sin \beta_{k / c l}
$$

Descending time and distance:

- Time:

$$
t_{k / d e / .}\left(H_{k / c r}-H_{k / d e}\right)=\frac{\left(H_{k / c r}-H_{k / d e}\right)}{R / D(H)}=(1 / b)\left\{\begin{array}{c}
\ln \left[a\left(H_{k / c r}\right)-b \cdot\left(H_{k / d e}\right]-\right. \\
\ln \left[a\left(H_{k / d e}\right)-b \cdot H_{k / d e}\right)
\end{array}\right\}
$$

The aircraft rate of descent $R / D(H)$ is expressed as: $\mathrm{R} / \mathrm{D}(\mathrm{H})=-\mathrm{a}+\mathrm{b} \cdot \mathrm{H}$, i.e., as approximately linearly increasing with the decrease of altitude $\left((H)\right.$ is the altitude $-10^{3}$ feet) $)^{(8)}$.

- Distance:

$$
r_{k / d e / .}=\left(H_{k / c r}-H_{k / d e}\right) / \sin \beta_{k / d e}
$$


Cruising time and distance:

$$
t_{k / c r / .}=\left(R_{k}-r_{k / c l / .}-r_{k / d e / .}\right) / v_{k / c r}
$$

The LTO (Landing and Taking-Off) cycle

The LTO cycle $\left(t_{k / / L T O}\right)$ includes the time of taxing out, take-off, landing, and taxing in time. It can be standardised for the supersonic aircraft similarly as for their subsonic counterparts $^{(60)}$.

$$
\begin{aligned}
& R_{k} \quad \text { length of route }(k) \text { between the origin and destination airport of a given } \\
& \text { flight }(\mathrm{nm}, \mathrm{km}) \\
& r_{k / c l} \text {. segment of route }(k) \text { enabling the aircraft of either category to climb to } \\
& \text { cruising altitude and accelerate from the take-off to the cruising speed } \\
& (\mathrm{nm}, \mathrm{km}) \\
& r_{k / d e / . \quad} \quad \text { segment of route }(k) \text { enabling the aircraft of either category to descend } \\
& \text { from the cruising altitude and decelerate from the cruising to the final } \\
& \text { approach speed (nm, km) } \\
& H_{k / c l}, H_{k / c r} \quad \text { take-off and cruising altitude, respectively, on route }(k) \text { operated by the } \\
& \text { aircraft of either category ( } \mathrm{ft}, \mathrm{m} \text { ) } \\
& R / C\left(H_{k / c r}-H_{k / c l}\right) \quad \text { rate of climb of the aircraft of either category from the take-off to } \\
& \text { the cruising altitude }\left(H_{k / c l}\right) \text { and }\left(H_{k / c r}\right) \text {, respectively, along route }(k) \\
& \text { (ft/min); } \\
& H_{k / c r}, H_{k / d e} \quad \text { cruise and the final approach and landing altitude, respectively, on route } \\
& \text { (k) operated by the aircraft of either category ( } \mathrm{ft} \text { ) } \\
& R / D\left(H_{k / c r}-H_{k / d e}\right) \quad \text { rate of descent of the aircraft of either category from the cruising to the } \\
& \text { final approach altitude }\left(H_{k / c r}\right) \text { and }\left(H_{k / d e}\right) \text {, along route }(k)(\mathrm{ft} / \mathrm{min}) \text {; } \\
& v_{k / c r} \quad \text { cruising speed of an aircraft of either category on route }(k)(\mathrm{kt}, \mathrm{km} / \mathrm{h}) \\
& \beta_{k / c l}, \quad \beta_{k / d e} \quad \text { climb and descent angle, respectively, of the corresponding segments of } \\
& \text { the route }(k) \text { operated by the aircraft of either category }\left({ }^{\circ}\right)
\end{aligned}
$$

\section{Appendix III: Models for estimating fuel consumption of supersonic flight(s) on a given route}

Four forces generally act on an aircraft in flight: thrust, aerodynamic drag, lift, and weight. They are always in balance, enabling safe flight. The lift force always balances the aircraft weight and the thrust force balances the aircraft aerodynamic drag and partially the component of its weight during the taking-off, climbing, descending, and landing phase. The thrust force during the climbing, cruising, and descending phase of flight is relevant for estimating the energy consumption in the given context ${ }^{(28),(61)}$.

\section{A-III: Climbing}

- Thrust (N)

$$
T_{c l}=m_{c l} \cdot a_{c l}+0.5 \cdot C_{d / c l}\left(\bar{v}_{c l}\right) \cdot \bar{\rho}_{c l} \cdot \bar{v}_{c l}^{2} \cdot A+m_{c l} \cdot g \cdot \sin \bar{\beta}_{c l}
$$




$$
\begin{gathered}
m_{c l}=m_{t o}-F C_{t o} \\
\bar{v}_{c l}=\left(v_{c r}-v_{t o}\right) / 2 \\
m_{c l}^{*}=m_{t o}-F C_{t o}-1 / 2 \cdot F C_{c l / 0}
\end{gathered}
$$

- $\operatorname{Energy}(\mathrm{J})$

$$
E_{c l}=T_{c l} \cdot r_{c l}
$$

- Fuel consumption $(\mathrm{kg})$

$$
F C_{c l}=\left(1 / \eta_{c l}\right) \cdot\left(E_{c l} / e_{f}\right)
$$

$A \quad$ aircraft fuselage area $\left(\mathrm{m}^{2}\right)$

$m_{c l} \quad$ initial aircraft mass during the climbing phase $(\mathrm{kg})$

$a_{c l}{ }^{+} \quad$ average longitudinal acceleration during the climbing phase $\left(\mathrm{m} / \mathrm{s}^{2}\right)$

$C_{d / c l}\left(\bar{v}_{c l}\right) \quad$ coefficient of aerodynamic drag during the climbing phase at average speed $\left(\overline{\mathrm{v}}_{\mathrm{cl}}\right)(-)$

$\bar{v}_{c l} \quad$ average aircraft speed during the climbing phase $(\mathrm{m} / \mathrm{s})$

$r_{c l} \quad$ length of the climbing segment of the route $(\mathrm{m})$

$e_{f} \quad$ specific energy of the given fuel used $(\mathrm{J} / \mathrm{kg})(\mathrm{J}-\mathrm{Joule})$

$\bar{\rho}_{c l} \quad$ average air density along the climbing segment of the route $\left(\mathrm{kg} / \mathrm{m}^{3}\right)$

$\bar{\beta}_{c l} \quad$ climbing angle $\left({ }^{\circ}\right)$

$\eta_{c l} \quad$ propulsion efficiency of the aircraft engines during the climbing phase

\section{B-III: Cruising}

- Thrust (N)

$$
\begin{gathered}
T_{c r}=q \cdot A_{w} \cdot C_{D 0}+\frac{\left(m_{c r} \cdot g\right)^{2}}{q \cdot \pi \cdot b^{2}}+\frac{128 \cdot q \cdot V o l^{2}}{\pi \cdot l^{4}}+\frac{\left(M^{2}-1\right) \cdot\left(m_{c r} \cdot g\right)^{2}}{q \cdot \pi \cdot l^{2}} \\
m_{c r}=m_{t o}-F C_{t o}-F C_{c l} \\
V o l \approx \pi \cdot r^{2} \cdot l
\end{gathered}
$$

- $\operatorname{Energy}(\mathrm{J})$

$$
E_{c r}=T_{c r} \cdot r_{c r} \text { and } r_{c r}=R_{k}-r_{c l} \cos \beta_{c l}-r_{d e} \cos \beta_{d e}
$$

- Fuel consumption $(\mathrm{kg})$

$$
F C_{c r}=\left(1 / \eta_{c r}\right) \cdot\left(E_{c r} / e_{f}\right)
$$

$\begin{array}{ll}q & \text { dynamic pressure }\left(\mathrm{N} / \mathrm{m}^{2}\right)(\mathrm{N}-\text { Newton }) \\ A_{w} & \text { reference wing area }\left(\mathrm{m}^{2}\right)\end{array}$ 


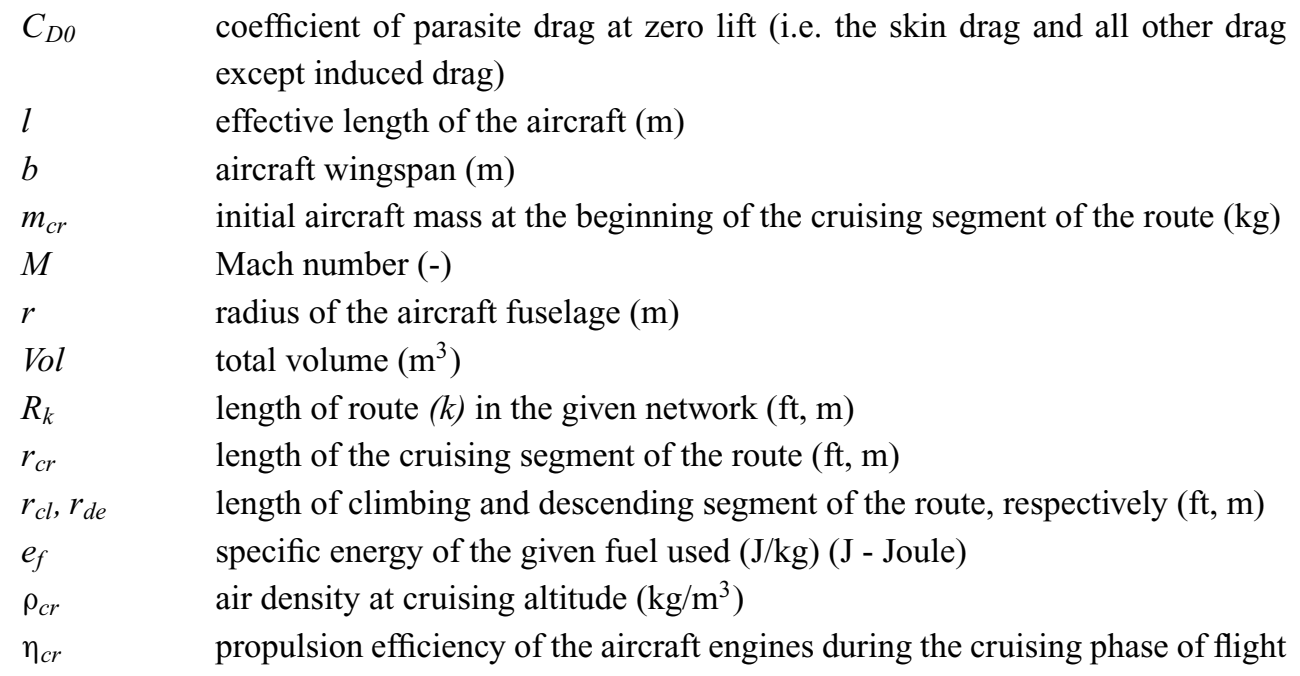

\section{C-III: Descending}

- Thrust (N)

$$
\begin{gathered}
T_{d e}=m_{d e} \cdot a_{d e}+0.5 \cdot C_{d / d e}\left(\bar{v}_{d e}\right) \cdot \bar{\rho}_{d e} \cdot \bar{v}_{d e}^{2} \cdot A-m_{d e} \cdot g \cdot \sin \bar{\beta}_{d e} \\
m_{d e}=m_{t o}-F C_{t o}-F C_{c l}-F C_{c r} \\
\bar{v}_{d e}=\left(v_{c r}-v_{l d}\right) / 2 \\
m_{d e}^{*}=m_{t o}-F C_{t o}-F C_{c l}-F C_{c r}-1 / 2 \cdot F C_{d e}
\end{gathered}
$$

- $\operatorname{Energy}(\mathrm{J})$

$$
E_{d e}=\left(\frac{1}{\eta_{d e}}\right) \cdot T_{d e} \cdot r_{d e}
$$

- Fuel consumption ( $\mathrm{kg})$

$$
F C_{d e}=\left(1 / \eta_{d e}\right) \cdot\left(E_{d e} / e_{f}\right)
$$

$\begin{array}{ll}m_{d e} & \begin{array}{l}\text { initial aircraft mass during the descending phase }(\mathrm{kg}) \\ \text { average aircraft longitudinal deceleration during the descending phase }\left(\mathrm{m} / \mathrm{s}^{2}\right) \\ a_{d e}{ }^{-}\end{array} \\ C_{d / d e}\left(\bar{v}_{d e}\right) & \begin{array}{l}\text { coefficient of aerodynamic drag during the descending phase at the average } \\ \text { speed }\left(\overline{\mathrm{v}}_{\mathrm{de}}\right)(-)\end{array} \\ \bar{v}_{d e} & \begin{array}{l}\text { average aircraft speed during the descending phase }(\mathrm{m} / \mathrm{s}) \\ \text { specific energy of the given fuel used }(\mathrm{J} / \mathrm{kg})(\mathrm{J}-\mathrm{Joule})\end{array} \\ e_{f} & \begin{array}{l}\text { length of the descending segment of the route }(\mathrm{m}) \\ r_{d e}\end{array} \\ \bar{\rho}_{d e} & \begin{array}{l}\text { average air density along the descending segment of the route }\left(\mathrm{kg} / \mathrm{m}^{3}\right) \\ \bar{\beta}_{d e}\end{array} \\ \eta_{d e} & \begin{array}{l}\text { descending angle }\left(^{\circ}\right) \\ \text { is the propulsion efficiency of the aircraft engines during the descending phase }\end{array}\end{array}$

